\title{
REVIEWS
}

\section{Imaging of the pulmonary manifestations of systemic disease}

\author{
A G Rockall, D Rickards, P J Shaw
}

Lung involvement in systemic disease may be a manifestation of the underlying pathological process, may be a complication of the underlying disease or may be related to the treatment. Lung pathology is dominant in certain diseases, such as in Wegener's granulomatosis, but may be only rarely present, for example in Henoch-Schönlein purpura. However, lung involvement has a profound effect on prognosis and may be challenging to accurately diagnose. In some patients, bronchoalveolar lavage and tissue diagnosis with transbronchial or percutaneous biopsy is not possible, due to the poor clinical state of the patient.

Imaging often plays a central part when lung involvement is suspected clinically and this role has increased with the advent of high resolution computed tomography (HRCT). The chest radiograph may provide diagnostic information and be useful in follow up but it is relatively insensitive. HRCT now has several established roles:

(1) May be diagnostic and if not will often narrow the differential diagnosis. ${ }^{12}$ This in turn may reduce the need for biopsy. ${ }^{3}$ The HRCT signs of interstitial lung disease, small airways disease and bronchiectasis are well established (see box 1).

(2) May demonstrate pathology when the chest radiograph appears normal, in patients with respiratory symptoms or abnormal pulmonary function tests. This particularly applies to diseases in which the radiographic signs are subtle or obscured by overlying structures, for example obliterative bronchiolitis, bronchiectasis, early fibrosing alveolitis, and fine walled cystic structures, such as in lymphangioleiomyomatosis.

(3) Assessment of disease activity. Several studies suggest that ground glass shadowing on HRCT in fibrosing alveolitis corresponds histologically to active alveolitis. ${ }^{4}$ This in turn predicts a better response to treatment ${ }^{5}$ and better prognosis. ${ }^{6}$ Although ground glass shadowing is non-specific, it often represents reversible pathology, such as infection, haemorrhage, or oedema.

(4) Assessment of interval change and treatment response, by acquiring comparative scans on follow up.

(5) Prognostic information.

(6) Planning a biopsy: for example transbronchial biopsy in peribronchial disease or percutaneous in subpleural disease and in guiding the optimal site for open biopsy, by defining areas of active alveolitis and avoiding areas of established fibrosis.

\section{Box 1: HRCT signs (adapted from Webb et $a l^{223}$ p 118, 207, 243)}

Fibrosing alveolitis

1. Findings of fibrosis: intralobular interstitial thickening, irregular interfaces, visible intralobular bronchioles, honeycombing, traction bronchiectasis. *

2. Irregular interlobular septal thickening.

3. Ground glass opacity.

4. Peripheral and subpleural predominance of abnormalities. ${ }^{\star} \dagger$

5. Lower lung zone and posterior predominance. ${ }^{\star} \dagger$

Bronchiectasis

1. Bronchial dilatation. ${ }^{\star} \dagger$

2. Bronchial wall thickening. ${ }^{\star} \dagger$

3. Visibility of peripheral airways. ${ }^{\star} \dagger$

4. Contour abnormalities ${ }^{\star}+$-for example, signet ring (vertically orientated bronchi), tram tracks (horizontally orientated bronchi), loss of tapering.

5. Fluid filled bronchi. ${ }^{\star} \dagger$

6. Atelectasis.

Bronchiolitis obliterans organising pneumonia (BOOP)

1. Patchy bilateral airspace consolidation. ${ }^{\star}$

2. Ground glass opacity. ${ }^{\star}$

3. Subpleural and/or peribronchovascular distribution.*

4. Bronchial wall thickening, dilatation in abnormal areas. *

5. Small nodular opacities, often peribronchiolar.

6. Combination of findings 1 and 2. ${ }^{\star} \dagger$

Obliterative bronchiolitis

1. Areas of decreased lung opacity, patchy in distribution. ${ }^{\star}$

2. Bronchiectasis. ${ }^{\star}$

3. Attenuation of pulmonary vessels. ${ }^{\star}$

4. Combination of 1-3.†

5. Areas of consolidation or increased lung opacity.

6. Reticulonodular opacities.

${ }^{\star}$ Most common findings; $†$ findings most helpful in differential diagnosis

(7) Prospective HRCTstudies may help in understanding the natural history of lung involvement in systemic disease.

Recently, several groups have published HRCT findings in several of the systemic diseases. This evidence based article reviews the radiological features of lung involvement, including the recent literature on HRCT

Neurofibromatosis

lymphangioleiomyomatosis 


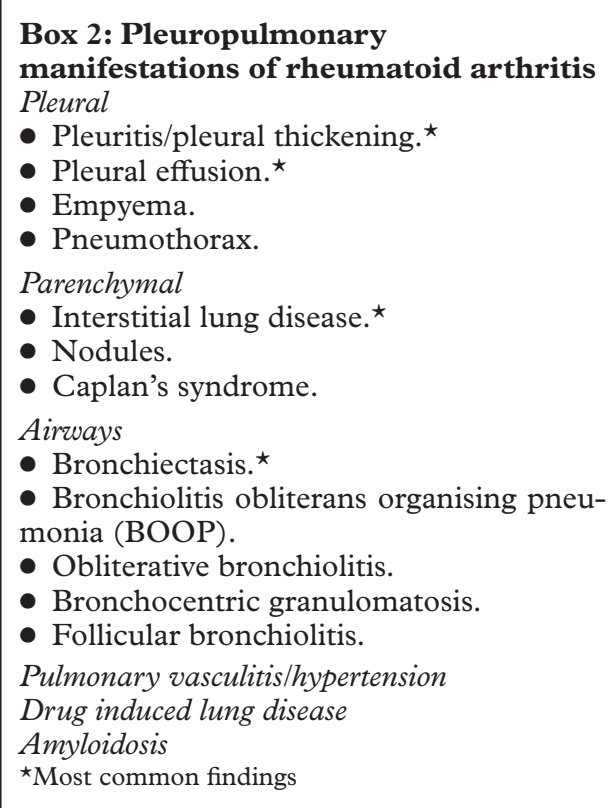

appearances, in the connective tissue diseases, systemic vasculitides and miscellaneous systemic diseases with lung involvement.

\section{Section A: connective tissue diseases} RHEUMATOID ARTHRITIS

The lungs, heart, and the vascular endothelium may be involved in rheumatoid arthritis. There is a strong association with a positive rheumatoid factor when systemic manifestations or vasculitis are present. Pulmonary involvement (box 2) is significant prognostically. In a large autopsy study, Tyoshina et al reported that lung involvement was second to infection as the most common cause of death $(18 \% v 27 \%){ }^{7}$

Pleural disease

Pleural disease is common in postmortem studies $(40 \%-75 \%)^{89}$ and is associated with subcutaneous nodules, interstitial lung disease and pericarditis, in middle aged men with high rheumatoid factor titres. ${ }^{9-11}$ Effusions, seen in $3 \%-5 \%,{ }^{12}$ usually occur at periods of active arthritis but may precede the arthritis. ${ }^{13}$ They are usually small, unilateral ${ }^{14}$ and asymptomatic, with mild pain in $20 \%-28 \% .^{15}$ They often resolve over weeks but may be persistent and recurrent. ${ }^{16}$ Pleural thickening is seen on chest radiography in $20 \%{ }^{17}$ Analysis of the pleural fluid may be helpful diagnostically. ${ }^{18}$ Pneumothorax and empyema are unusual findings ${ }^{19}{ }^{20}$ and may be secondary to cavitation of a necrobiotic nodule. A spontaneous sterile empyema may develop during active rheumatoid arthritis. ${ }^{19}$

\section{Parenchymal disease}

Interstitial lung disease-The association of fibrosis and rheumatoid arthritis (RA-ILD) is well established. The prevalence varies depending on the diagnostic criteria: chest radiograph abnormalities occur in $1 \%-6 \%{ }^{11} 121821$;

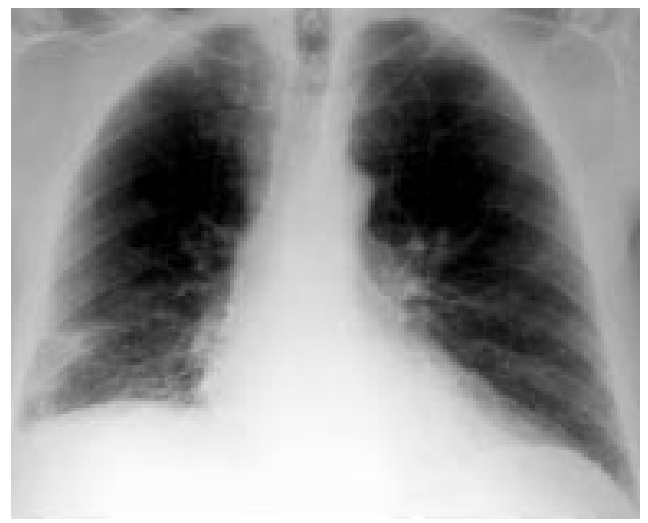

Figure 1 Chest radiograph of a 60 year old man, with rheumatoid arthritis and progressive dyspnoea, showing signs of fibrosing alveolitis with basal volume loss and reticular opacities, more pronounced on the right (courtesy of Dr H Booth).

pulmonary function test abnormalities in $40 \%{ }^{11}{ }^{22}$; and histological changes in $80 \%$ of patients, including some asymptomatic patients with a normal chest radiograph. ${ }^{23}$

There is a male preponderance $(2 \mathrm{M}: 1 \mathrm{~F})$ with an insidious onset in the 50s, with a cough and/or dyspnoea. Patients are usually seropositive, with established joint disease in $90 \%$, and have subcutaneous nodules and finger clubbing. ${ }^{11}$ Over $70 \%$ of patients are smokers.

The appearances on chest radiography are indistinguishable from cryptogenic fibrosing alveolitis, with bibasal reticular, reticulonodular, or honeycomb interstitial opacities and progressive volume loss but may be asymmetric (fig 1). ${ }^{12} 21$ Pleural abnormalities and pulmonary nodules, if present, may help to distinguish RA-ILD from cryptogenic fibrosing alveolitis. ${ }^{11}$

HRCT demonstrates interstitial lung disease in patients with and without clinical evidence of the disease $(69 \%-80 \%$ and $20 \%-29 \%))^{21}{ }^{24}$ The signs are those of cryptogenic fibrosing alveolitis (fig 2, box 2). ${ }^{18} 21{ }^{25}$ Follow up HRCT demonstrates progressive honeycombing from the lung bases towards the apices. ${ }^{21}$ Emphysema and bronchiectasis have been reported in association with RA-ILD, including nonsmoking patients. ${ }^{24-26}$

Diffuse interstitial pulmonary amyloidosis may mimic interstitial lung disease and should be considered in the differential diagnosis in cases with longstanding rheumatoid arthritis. ${ }^{27}$

Computed tomography is used to direct biopsy towards areas of presumed active alveolitis (ground glass areas). Histology is often mixed, including interstitial pneumonitis, bronchiolitis obliterans organising pneumonia (BOOP), lymphocytic interstitial pneumonitis, lymphoid hyperplasia, and rheumatoid nodules. ${ }^{18}$ The features are similar to cryptogenic fibrosing alveolitis except for an increase in lymphoid follicles, which is suggestive of RA-ILD or the presence of rheumatoid nodules (pathognomonic for rheumatoid arthritis).

The course of RA-ILD is variable, usually being slowly progressive, and pulmonary hypertension may develop. The prognosis is poorer than in nodular disease or BOOP. ${ }^{18}$ 


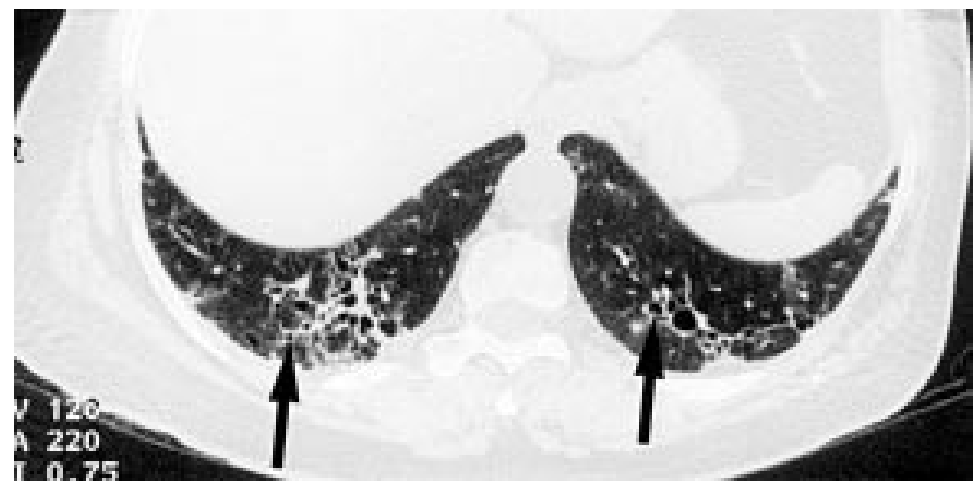

Figure 2 A 66 year old woman with rheumatoid arthritis. HRCT demonstrates peripheral basal fibrosis with architectural distortion and traction bronchiectasis (arrows) (courtesy of Dr H Booth).
Pulmonary nodules-Rheumatoid nodules are more common in men, usually in smokers with subcutaneous nodules, and high rheumatoid factor titres. ${ }^{11}$ Patients are usually asymptomatic, although large nodules may rupture into the pleural space. ${ }^{11}{ }^{19-21}$ The appearance of nodules does not necessarily reflect overall disease activity ${ }^{11}$ and may antedate the onset of arthritis. ${ }^{9829}$ Histologically, they are identical to subcutaneous nodules and are pathognomonic of rheumatoid arthritis. ${ }^{14}$

Nodules are identified in less than $1 \%$ of chest radiographs, ${ }^{9}$ in $22 \%$ on computed tomography, ${ }^{21}$ but are seen pathologically in $32.5 \% .^{30}$ Radiographic features of rheumatoid arthritis nodules are non-specific being located subpleurally, usually multiple and range from a few millimetres to several centimetres in diameter. ${ }^{11213031}$ Cavitation, occurring in approximately $50 \%$, may be associated with pneumothorax, pleural effusion, or empyema after rupture into the pleural space; calcification is rare.

Nodules cause diagnostic problems, raising the possibility of a primary or secondary malignancy. ${ }^{13} 32$ They have been reported to take up radio-iodine ${ }^{33}$ and fluorine-18fluorodeoxyglucose in positron emission tomography imaging. ${ }^{34}$ Regression, with time or during treatment (with steroids) may be helpful in the diagnosis, as rheumatoid arthritis nodules usually run a benign course. However, cytological/histological confirmation is advocated by some authors ${ }^{31}$ particularly as lymphoma and lung cancer are reported to occur with a higher incidence in rheumatoid arthritis. $^{35}$

Caplan's syndrome-The association of rheumatoid arthritis with pulmonary nodules and coal miner's pneumoconiosis was first described by Caplan in $1953,{ }^{36}$ with a similar syndrome reported with other inorganic dusts such as silica and asbestosis. ${ }^{9}$ Peripheral, well defined, solitary or multiple nodules often appear rapidly in crops at times of increased rheumatoid arthritis activity and are often associated with new subcutaneous nodules. Biopsy reveals inorganic dust within the necrotic nodule. The nodules are asymptomatic and do not require treatment unless a complication develops following rupture of a cavitating lesion into the pleural space. ${ }^{36}$
Airways disease

A strong association between rheumatoid arthritis and airways disease has been demonstrated on pulmonary function tests. ${ }^{37}$ Geddes et al found that $38 \%$ of patients with a normal chest radiograph had airflow obstruction. ${ }^{37}$ One explanation for this is recurrent chest infections but small airways disease has been demonstrated histologically with no history of chest infections or smoking. ${ }^{38}$

Radiologically, bronchiectasis in rheumatoid arthritis has been described in several series and may precede the onset of rheumatoid arthritis. ${ }^{21}{ }^{39} 40$ It may be secondary to interstitial fibrosis (traction bronchiectasis) or isolated. ${ }^{40}$ Although insensitive, the commonest chest radiograph appearance is of bibasal linear markings and focal infiltrates. ${ }^{39}$ On computed tomography, bronchiectasis and bronchiolectasis have been demonstrated in $30 \%$ of unselected patients. ${ }^{21}$ On HRCT, peribronchovascular micronodules, forming a "tree-in-bud" appearance, in non-smokers may correspond to small airways disease (see box 1 ). Interestingly, HRCT features of small airways disease was noted in 20 of 33 patients with normal pulmonary function tests suggesting that HRCT is more sensitive than these tests. ${ }^{40}$ In this study, $70 \%$ of patients were smokers.

$B O O P$ - May be seen in rheumatoid arthritis, affecting middle aged women with established seropositive rheumatoid arthritis. ${ }^{14}$ Histologically, there is a proliferative bronchiolitis with intraluminal granulation tissue in the distal bronchioles, alveolar ducts, and alveoli. ${ }^{41}$ Presentation is non-specific (subacute onset of cough, dyspnoea, and low grade fever), with restrictive pulmonary function tests and a reduced diffusion capacity. The chest radiograph shows bilateral, patchy, peripheral, ill defined alveolar/acinar or linear opacities. HRCT additionally demonstrates ground glass opacities and small nodular opacities in a peribronchial and peribronchiolar distribution and bronchial wall thickening. ${ }^{42}$ Infection must be ruled out and empirical treatment with antibiotics is often used. Diagnosis is by biopsy. There is a good response and prognosis with steroids. ${ }^{414} 44$

Obliterative bronchiolitis-This is rare and may occur as a primary feature of rheumatoid arthritis or secondary to drug therapy such as D-penicillamine. It carries a poor prognosis. ${ }^{45}$ It usually affects women with well established rheumatoid arthritis and positive rheumatoid factor, who present with a dry cough and rapidly progressive dyspnoea. There are reduced breath sounds and faint basal crackles. Pulmonary function tests demonstrate airflow limitation with an increased total lung capacity and preserved diffusion capacity. Histology demonstrates intense inflammation and obliteration of the terminal and respiratory bronchioles with sparing of the alveoli. ${ }^{46}$

The chest radiography may be normal, overinflated, or infrequently demonstrate patchy interstitial lung disease (fig 3A). HRCT demonstrates a mosaic attenuation pattern, with marked inhomogeneity of lung density in adjacent pulmonary lobules, in a geometrical 

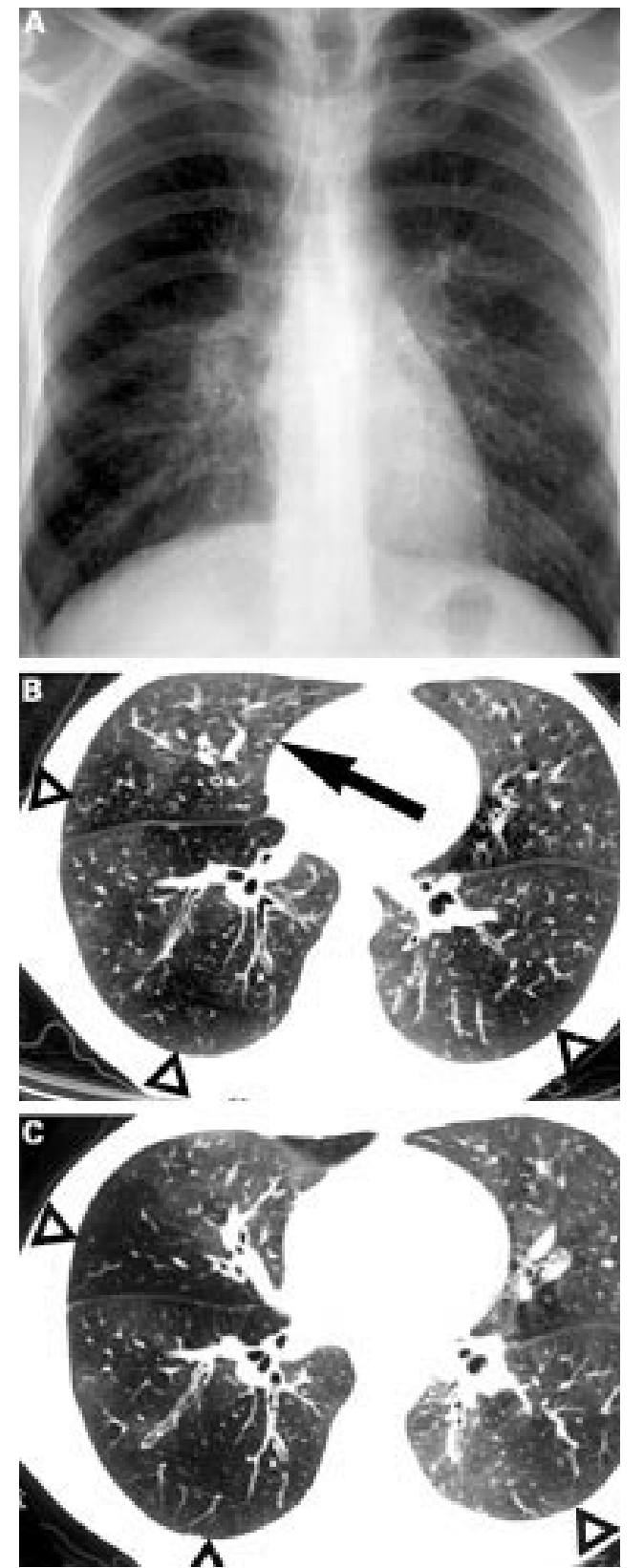

Figure 3 A 37 year old markedly dyspnoeic man with rheumatoid arthritis. (A) Chest radiograph demonstrates reduced vascularity in the right upper zone and bronchial wall thickening in the lower lobes. The suspected diagnosis was obliterative bronchiolitis. (B) HRCT in inspiration demonstrates a mosaic attenuation pattern with normal parenchyma (arrow) and extensive areas of reduced vascularity (arrowheads), highly suggestive of obliterative bronchiolitis. (C) HRCT in expiration confirms the diagnosis by demonstrating air trapping in the areas of reduced vascularity (arrowheads).

pattern (fig 3B, box 1).$^{46}$ Expiratory scans confirm air trapping (fig 3C).

Bronchocentric granulomatosis-This is a granulomatous inflammation of the airways, usually associated with asthma and aspergillus and, rarely, associated with rheumatoid arthritis. ${ }^{47}{ }^{48}$ Presentation is with dyspnoea, cough, haemoptysis, and chest pain. Imaging reveals unilateral or bilateral nodules, measuring several centimetres, possibly with cavitatation, which are bronchocentric in distribution on computed tomography. Histologically the features are similar to rheumatoid arthritis nodules. Nodules may remain static or resolve with steroids. ${ }^{47}$

Follicular bronchiolitis is lymphoid follicular hyperplasia along the airways. It is seen uncommonly and probably manifests as reticulonodular opacities on chest radiography. ${ }^{30}$

\section{Pulmonary vasculitis}

Pulmonary vasculitis, rarely seen in rheumatoid arthritis, may occur with a systemic vasculitic process with cutaneous and renal involvement or, less commonly, is isolated to the lungs. ${ }^{49}$ Histology demonstrates a necrotising vasculitis affecting small to medium sized arteries or rarely, a necrotising capillaritis with immune complex deposition. ${ }^{49}$

Patients present with dyspnoea, cough, occasionally haemoptysis or acute respiratory failure. ${ }^{1149}$ The chest radiograph may be normal, demonstrate interstitial opacities or signs of pulmonary hypertension (enlarged central pulmonary vessels with peripheral pruning). ${ }^{11}$ In rare cases of diffuse alveolar haemorrhage, focal or diffuse alveolar opacification may be seen. ${ }^{49}$

\section{Drug induced pulmonary disease}

Drug induced lung disease from methotrexate, gold, and D-penicillamine is difficult to diagnose, with no pathognomonic features. Other diagnoses must be excluded, particularly infection.

Methotrexate pneumonitis is a potentially serious condition with a prevalence of between $0.3 \%$ and $18 \%$, with a mean of $3.3 \%$ in an extensive review by Salaffi et al. ${ }^{50}$ Patients with pre-existing lung disease (such as interstitial lung disease or asthma), older age, diabetes, and smokers are at greater risk and are usually rheumatoid factor positive. ${ }^{1450}$ Presentation may be subacute, with dyspnoea, dry cough, fever, malaise and occasionally chest pain, with hypoxia.

The chest radiograph demonstrates diffuse bilateral usually basal interstitial or alveolar infiltrates. ${ }^{50}$ Lymphadenopathy and pleural effusions may suggest the diagnosis. ${ }^{51}{ }^{52} \mathrm{Com}-$ puted tomography demonstrates heterogeneous ground glass opacities and septal lines. ${ }^{50}$

Bronchoalveolar lavage excludes infection, particularly Pneumocystis carinii pneumonia, which may have similar clinical and radiological features and may complicate low dose methotrexate therapy. ${ }^{53}$

Gold induced pulmonary disease, usually an interstitial pneumonitis, has been rarely reported and is difficult to diagnose. A total of 140 reported cases were reviewed to assess the features which help to differentiate gold induced interstitial lung disease from RA-ILD and are female preponderance (6:1), low titres of rheumatoid factor, absence of subcutaneous nodules and finger clubbing, and the presence of fever and skin rash. ${ }^{54}$ The presenting symptoms were of dyspnoea, dry cough, fever, and occasionally cyanosis. 


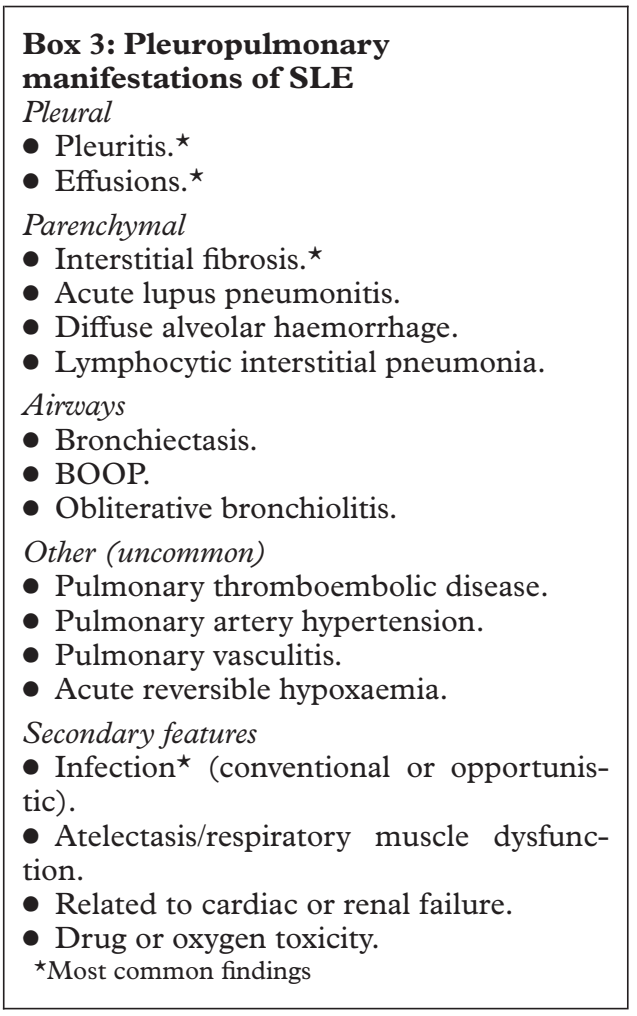

The chest radiograph shows diffuse interstitial infiltrates. Computed tomography demonstrates bronchocentric alveolar opacities, which may be helpful, as the changes from RA-ILD are predominantly peripheral. Cysts and high attenuation nodules may be seen in a subpleural distribution. ${ }^{54}$

Treatment of methotrexate pneumonitis and gold induced interstitial lung disease and discontinuation of the drug usually results in a very good response clinically and radiologically but fatalities have been reported. ${ }^{51} 5354$

D-penicillamine has been associated with interstitial lung disease and it may cause an obliterative bronchiolitis with significant morbidity and mortality and therefore drug withdrawal together with aggressive treatment may be required. ${ }^{14}$

SYSTEMIC LUPUS ERYTHEMATOSUS (SLE)

This type III immune complex disease is characterised by inflammatory changes in connective tissues, blood vessels, and serosal surfaces. It affects women of childbearing age $(\mathrm{F}: \mathrm{M}=10: 1)$ and is more common in black women (3:1), presenting with widely diverse clinical manifestations.

Pulmonary involvement

The lungs are commonly involved (box 3), although there are wide variations in the reported prevalence depending on criteria: series based on clinical findings report an incidence of $50 \%-70 \%{ }^{11}$; pulmonary function tests demonstrate $88 \%$ of unselected patients having a reduced diffusion capacity. ${ }^{55}$ In this same series, abnormal chest radiography was noted in $38 \%$ of patients. At autopsy, pleuroparenchymal changes attributable to SLE were found in $22 \%$ of patients. Pulmonary changes related to infection (44\%), cardiac or renal failure, or oxygen toxicity were also found. ${ }^{56}$

Clinical manifestations include cough, dyspnoea and pleuritic chest pain, the latter being accompanied by fever. ${ }^{11} 5758$

\section{Lupus pleuritis/effusions}

Pleuritis is the commonest pleuropulmonary manifestation, occurring in $30 \%-60 \%$ of patients at some stage, usually in established disease and usually associated with pain and pleural effusions..$^{59}{ }^{60}$ Effusions are usually bilateral and small. Residual pleural thickening may occur and is reported in up to $70 \%$ of chest radiographs of symptomatic patients ${ }^{57}$ but is unusual in asymptomatic patients. ${ }^{61}$

On HRCT, pleural and pericardial thickening or irregularity were reported in $13 \%$ of asymptomatic patients, $24 \%$ of unselected patients, and in $87 \%$ of patients with respiratory symptoms. ${ }^{57} 6162$

Pleural fluid is a serous or serosanguinous exudate and immunological analysis helps in the differential diagnosis. ${ }^{63}$ Effusions may be secondary and an infective aetiology must be excluded. They usually resolve spontaneously, although corticosteroids provide rapid symptomatic relief. ${ }^{59}$

\section{Parenchymal disease}

Interstitial fibrosis-Only $1 \%-6 \%$ of patients have evidence of interstitial lung disease clinically or on chest radiography. ${ }^{616465}$ The prevalence is higher in autopsy studies ${ }^{66}$ and on HRCT, with signs of interstitial lung disease seen in $60 \%$ of symptomatic patients, ${ }^{57}$ in $38 \%$ of asymptomatic patients with normal chest radiography, ${ }^{61}$ and in $32 \%$ of unselected patients. ${ }^{67}$

The chest radiography and HRCT signs are similar to those of cryptogenic fibrosing alveolitis. ${ }^{57}$ In one HRCT study, nine of 11 patients with an abnormal HRCT were asymptomatic, seven had a normal chest radiograph, and four had normal pulmonary function tests. ${ }^{67}$ This increased senstivity of HRCT for the detection of early interstitial lung disease has also been found with rheumatoid arthritis ${ }^{24}$ and systemic sclerosis. ${ }^{68}$ Interstitial lung disease usually follows an insidious course but may lead to respiratory failure.

Acute lupus pneumonitis-This is uncommon but life threatening, with an estimated incidence of $1 \%-4 \% .{ }^{64}$ The diagnosis is one of exclusion from infection, acute pulmonary oedema, haemorrhage, or infarction. Patients are extremely ill, with fever, tachypnoea, and hypoxia. The chest radiograph reveals ill defined, bilateral patchy air space consolidation in a peripheral, basal distribution, which rarely cavitates. There may be an effusion. ${ }^{11}$ A normal chest radiograph does not exclude the diagnosis. ${ }^{69}$ On HRCT, ground glass opacities have been attributed to acute lupus pneumonitis, but there is limited biopsy correlation. ${ }^{57}$

Histology demonstrates diffuse alveolar damage and interstitial oedema. An incomplete 
response to treatment carries a high mortality. ${ }^{69}{ }^{70}$ Clinical resolution is usually accompanied by complete radiographic clearing.

\section{Airways disease}

Airways disease in SLE, rarely identified on chest radiography, has been reported at autopsy. Gross et al found distal airways disease in all lung specimens and bronchiolar dilatation in $36 \%$ of specimens. ${ }^{71}$ HRCT demonstrates bronchiectasis or bronchial wall thickening in $20 \%-35 \%$ and centrilobular tree-in-bud opacities. ${ }^{576167}$ Increased susceptibility to infection may be the underlying cause of bronchiectasis. ${ }^{67}$

BOOP - This has rarely been reported with SLE, both during the course of the illness or as a presenting feature. ${ }^{42}{ }^{72}$ There is usually a good response to steroids. The differential diagnosis includes infection and acute lupus pneumonitis.

Pulmonary haemorrhage and vascular disease Diffuse alveolar haemorrhage-Asymptomatic pulmonary haemorrhage is a common autopsy finding ${ }^{66}$ and may be secondary to aspiration, congestive cardiac failure, renal failure, infection, and acute lupus pneumonitis. ${ }^{5673}$ Acute diffuse alveolar haemorrhage is uncommon but occurs in SLE more frequently than in other connective tissue diseases. ${ }^{74}$ This is a potentially fatal complication of SLE, with a mortality rate of approximately $60 \% .{ }^{73} 75$ Presentation is with dyspnoea, anaemia, and haemoptysis (in $42 \%-66 \%$ ). ${ }^{73}$ In a series of 510 hospital admissions for SLE, 3.7\% had diffuse alveolar haemorrhage and in $80 \%$ of these patients, pulmonary capillaritis was the cause. ${ }^{73}$ Differentiation between diffuse alveolar haemorrhage due to pulmonary capillaritis and other causes often requires lung biopsy. The histology is a diffuse alveolitis secondary to an immune complex capillaritis.

The chest radiograph findings are bilateral diffuse or patchy air space or reticulonodular opacities, usually sparing the apices, which may be migratory, and appear and resolve rapidly. ${ }^{76}$ Magnetic resonance has been reported to help diagnostically by demonstrating the signal characteristics of blood. ${ }^{77}$

Pulmonary hypertension - This is uncommon, seen in approximately $5 \%-14 \% .^{78}$ It is usually primary but may be secondary to recurrent thromboemboli, a complication of interstitial lung disease or a feature of SLE mixed connective tissue disease overlap syndrome. Cavitating consolidation may be seen in pulmonary infarction. Pulmonary hypertension in SLE is associated with antiphospholipid antibodies ${ }^{80}$ and the prognosis is variable. ${ }^{59}$

Rarities

Lymphocytic interstitial pneumonia, pseudolymphoma, obliterative bronchiolitis, acute reversible hypoxaemia, and hilar adenopathy are rarely seen..$^{58182}$ Pulmonary vasculitis is rare but may be the cause of a cavitating nodule. ${ }^{83}$
Secondary changes

Infection - This is the commonest pleuropulmonary manifestation, accounting for approximately $50 \%$ of pleuropulmonary disease and is the commonest cause of parenchymal opacities radiographically. ${ }^{11} 156681$ Infection may be life threatening, particularly with immunosuppressive treatment or renal failure. In one large autopsy series, $44 \%$ of patients had bronchopneumonia, $8 \%$ had aspiration pneumonia, and $7 \%$ had an opportunistic infection, including fungal and pneumoncystis pneumonia. ${ }^{56}$ An infective aetiology should always be excluded before diagnosing primary SLE related lung disease.

Diaphragm dysfunction/atelectasis-An elevated diaphragm and basal atelectasis in the absence of parenchymal abnormalities have been attributed to a diffuse diaphragmatic myopathy. ${ }^{84}$ This restrictive disorder presents with dyspnoea, and often orthopnoea, a symptom experienced by patients with diaphragmatic paralysis. ${ }^{84}$ Atelectasis may be secondary to pulmonary embolic disease or diaphragmatic splinting from painful pleuritis.

Pulmonary oedema may be secondary to renal or cardiac failure. Fluffy alveolar shadowing in the perihilar region and lower zones occurs with or without pleural effusions. The differential includes infection and acute lupus pneumonitis.

\section{Drug induced lupus}

Approximately $5 \%-10 \%$ of patients with drug induced SLE (commonly with procainamide and hydralazine) have lung disease, with pleural and pericardial effusions being the commonest manifestation. Prognosis is good once the drug is discontinued. ${ }^{86}$

SJÖGREN'S SYNDROME

This autoimmune syndrome is characterised by lymphocytic infiltration of the lacrimal and salivary glands. Other exocrine glands and extraglandular sites may be involved (in 5\%$10 \%{ }^{87}$ ). The syndrome may be primary or secondary, being associated with another autoimmune disease, commonly rheumatoid arthritis. It affects women ( $F: M=9: 1)$ over the age of 40 .

Pulmonary involvement (box 4) - This is estimated between $9 \%-90 \%{ }^{88-90}$ depending on diagnostic criteria and patient selection. Symptoms include persistent cough, dyspnoea, and recurrent chest infections. ${ }^{1189}$ In secondary Sjögren's, pulmonary features may be dominated by the associated connective tissue disease, with interstitial lung disease and less frequently, pleural disease..$^{92}$ In primary Sjögren's, pulmonary function tests, and HRCT have demonstrated that interstitial lung disease and small airways disease are common. ${ }^{93}{ }^{94}$ Interstitial lung disease may be due to fibrosing alveolitis $\left(8 \%-33 \%{ }^{90}{ }^{95}\right)$ or lymphocytic interstitial pneumonitis, which is found in $0.9 \%-42 \% .{ }^{90}{ }^{96}$ Airways disease is also multifactorial: tracheobronchial dessication leads to inspissated mucous and recurrent chest infections ${ }^{92}$; lymphocytic infiltration of the airways causes a follicular lymphocytic 


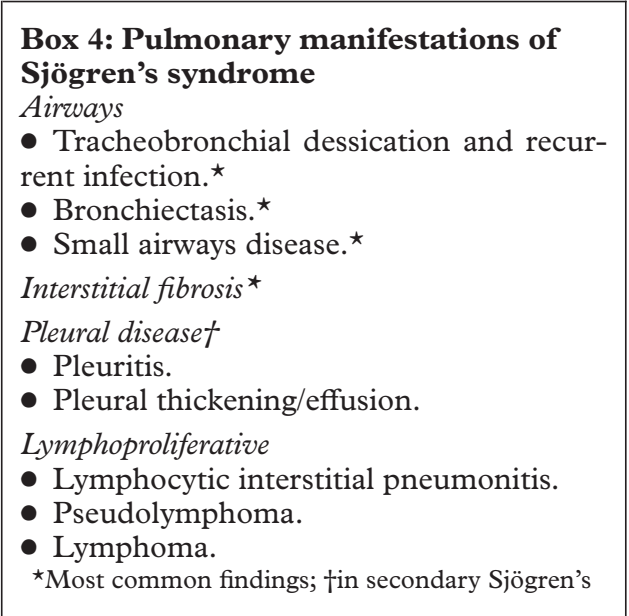

bronchitis in up to $31 \% .^{95}$ Lymphoproliferation, with mass-like aggregates of benign lymphocytes (pseudolymphoma) or lymphoma, ${ }^{87}$ usually non-Hodgkin's, may occur. Lymphoma is more frequent in primary Sjögren's, usually in the salivary glands, but is also reported in the lungs, in $1 \%-2 \% .^{919497}$ Rarities include BOOP, ${ }^{98}$ pulmonary amyloidosis, ${ }^{99}$ and pulmonary hypertension. ${ }^{100}$ The prognosis of pulmonary disease associated with primary Sjögren's is good unless a lymphoma develops. ${ }^{92}$

\section{Radiological features}

Chest radiography - Changes are reported in $5.5 \%-14 \% .^{94}{ }^{101}$ Basal reticular or reticulonodular opacities are seen in interstitial lung disease (fibrosing alveolitis or lymphocytic interstitial pneumonitis), ${ }^{94}{ }^{102}$ although associated air space shadowing is suggestive of lymphocytic interstitial pneumonitis. ${ }^{103}$ Bronchiectasis and pleural effusions ${ }^{1189} 91$ are reported in studies which included both primary and secondary Sjögren's. Enlarging mediastinal nodes and multiple nodular/air space opacities may indicate pseudolymphoma or lymphoma. ${ }^{89} 9194104$

HRCT - Findings in primary Sjögren's syndrome have been reported in non-smoking, predominantly asymptomatic patients. $^{94} 101$ HRCT demonstrated abnormalities in $28 \%$ $34 \%$. The commonest findings were small airways disease (bronchiolectasis, bronchial wall thickening, tree-in-bud appearance, and air trapping) and signs of fibrosing alveolitis. ${ }^{94101}$ One case with alveolar consolidation was confirmed as lymphoma. HRCT abnormalities occurred in $19 \%$ of asymptomatic patients. ${ }^{94}$ This concurs with bronchoalveolar lavage findings, in primary Sjögren's, of subclinical alveolar inflammation in $55 \% .{ }^{105}$

POLYMYOSITIS/DERMATOMYOSITIS (PM/DM)

This inflammatory condition of skeletal muscle and skin may be associated with another connective tissue disease or a neoplasm. ${ }^{106}$ It affects females ( $\mathrm{F}: \mathrm{M}=2: 1$ ) in the 30-60 age group. ${ }^{11}$ Systemic manifestations include arthropathy, pulmonary or cardiac disease.
Box 5: Pulmonary manifestations of PM/DM

- Aspiration pneumonia secondary to dysphagia.*

- Fibrosing alveolitis. ${ }^{\star}$

- BOOP.*

- Diffuse alveolar damage.

- Pneumonia/opportunistic infections.

- Malignancy, primary or metastatic.

- Ventilatory insufficiency secondary to muscular weakness.

${ }^{\star}$ Most common findings

Pulmonary involvement - This occurs in up to $50 \%$ of patients ${ }^{107} 108$ and is associated with significant morbidity and mortality. ${ }^{108}$ The pulmonary manifestations are listed in box 5 .

Aspiration pneumonia-Aspiration pneumonia secondary to dysphagia is common $(15 \%-$ $20 \%$ ) and potentially fatal. ${ }^{108}$ There is an impaired cough reflex due to muscle weakness involving the pharynx and oesophagus. ${ }^{109}$ Chest radiography demonstrates segmental air space consolidation in dependent areas.

Interstitial lung disease-This has a reported prevalence of $5 \%-30 \%$ depending on diagnostic criteria. ${ }^{107} 108{ }^{110}$ It may present concurrently, after, or, in up to a third of cases, before the diagnosis of PM/DM. ${ }^{111}{ }^{112}$ Presentation is commonly with insidious progressive dyspnoea but may be acute, or asymptomatic with abnormal chest radiography and pulmonary function tests.

Common histological patterns are BOOP, fibrosing alveolitis, and diffuse alveolar damage. ${ }^{113}$ Histology is helpful in predicting prognosis, BOOP having a relatively favourable prognosis compared with fibrosing alveolitis, with a uniformly poor prognosis in diffuse alveolar damage. However, there is a significant post-biopsy mortality and treatment is rarely altered. ${ }^{11}$

Chest radiography-The pattern is similar to crytpogenic fibrosing alveolitis, with basal reticular or reticulonodular opacities or mixed alveolar/ground glass and interstitial opacities. ${ }^{113}$ Progressive honeycombing may occur. BOOP and diffuse alveolar damage result in bilateral air space consolidation.

$H R C T$-HRCT appearances of PM/DM have been described. ${ }^{112} 114115$ Basal subpleural ground glass and linear opacities were seen in over $90 \%$ of patients who underwent computed tomography. Mid to lower zone patchy consolidation in subpleural or peribronchial regions, seen in $50 \%-100 \%$ of cases, usually correlated with BOOP where histology was available. ${ }^{112}$ These patients generally improved with steroid therapy, although honeycombing was occasionally seen on follow up. ${ }^{114}$ Diffuse alveolar damage was confirmed in a patient with diffuse ground glass and consolidation. ${ }^{112}$ Overall, peripheral air space consolidation and peribronchial thickening are fairly characteristic of pulmonary involvement in PM/DM and there is a relatively lower incidence of honeycombing. ${ }^{114} 115$ HRCT may prove to be of help in 
Box 6: Pulmonary manifestations of PSS $^{11} 1_{122-124}^{224} 225$

- Interstitial fibrosis. *

- Oesophageal dilatation ${ }^{\star} /$ aspiration pneumonia. *

- Pulmonary hypertension. *

- Infection.

- Mediastinal lymphadenopathy.

- Pleural thickening.

- Pleural and pericardial effusions.

- Diffuse alveolar haemorrhage.

${ }^{\star}$ Most common findings

predicting histology, assessing disease progression, and monitoring response to therapy. ${ }^{112} 114116$

Malignancy-There is a higher than expected incidence of neoplastic disease, particularly lung carcinoma, with a higher rate mortality from cancer in patients with dermatomyositis. ${ }^{117}$ Symptoms of PM/DM may predate the tumour by one to two years.

Respiratory muscle dysfunction-Respiratory muscle dysfunction resulting in respiratory failure is unusual (under 5\%) but minor impairment occurs more commonly, with recurrent pneumonia or mucous plugging. ${ }^{108}$ Chest radiography demonstrates elevated hemidiaphragms and basal atelectasis.

Rarities - These include pulmonary hypertension ${ }^{118}$ and pulmonary vasculitis/capillaritis with diffuse alveolar haemorrhage. ${ }^{119}$

PROGRESSIVE SYSTEMIC SCLEROSIS (PSS)

There is inflammation, fibrosis, and vascular changes in the skin, resulting in scleroderma, with variable multisystem involvement of other internal organs, usually affecting women in their 50 s to 60 s. Three clinical subgroups have been described ${ }^{120}$ : (1) classical PSS; (2) CREST syndrome; and (3) overlap syndromes in which PSS coexists with another connective tissue disease such as rheumatoid arthritis, SLE, or PM/DM.

Pulmonary involvement-This is prevalent (box 6) with changes in $74 \%-95 \%$ in autopsy studies and is a significant cause of morbidity and mortality, with exertional dyspnoea reported in a third of patients. ${ }^{68}$ Pulmonary involvement is less common with the CREST syndrome. ${ }^{121122}$

Interstitial fibrosis-This is the commonest manifestation, present in $20 \%-65 \% .{ }^{68}{ }^{123} \mathrm{Re}-$ strictive pulmonary function tests with a decreased diffusing capacity may precede clinical or radiographic changes. ${ }^{1122}$

Chest radiography - Changes, present in up to $65 \%$, are of cryptogenic fibrosing alveolitis (fig 4A) with progression from fine to coarse reticular opacities and honeycombing. ${ }^{68} 123$ Cystic lesions may result in spontaneous pneumothorax. $^{11}$

HRCT - This detects pulmonary abnormalities in $60 \%-91 \%$ of patients. ${ }^{68122} 124125$ The signs are those of cryptogenic fibrosing alveolitis (fig 4B). ${ }^{68122}{ }^{124}$ Subpleural cysts are noted in $17 \%$ of adults. ${ }^{68}$ Consolidation or masses are uncommon. $^{122}$

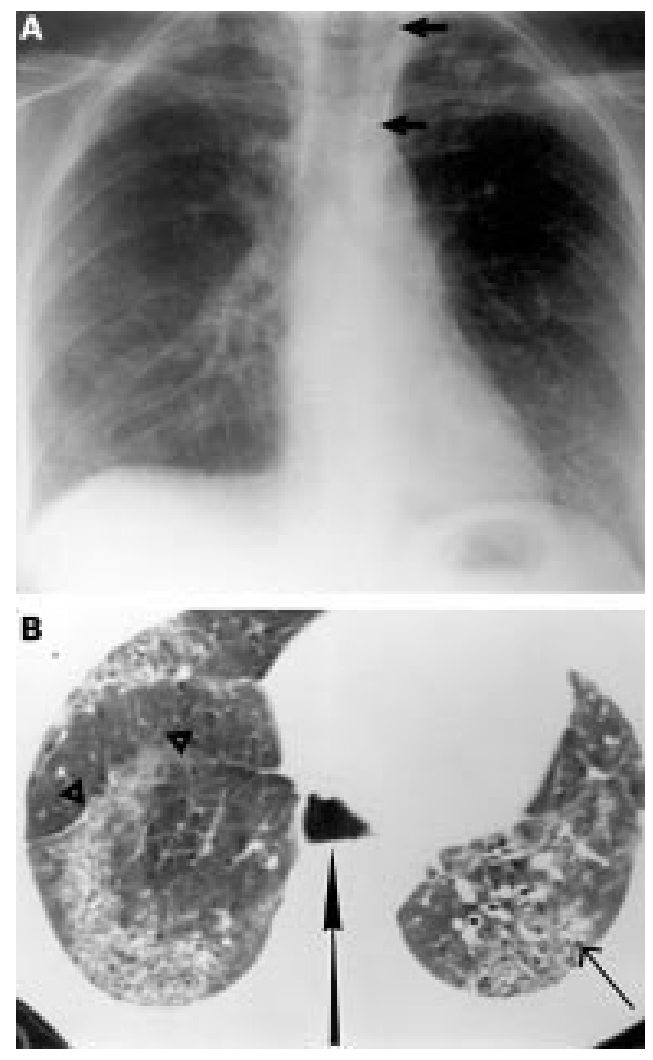

Figure 4 A 35 year old patient with PSS and dyspnoea. (A) Chest radiograph demonstrates bibasal symmetrical fine reticular opacities of fibrosing alveolitis with volume loss on the right and a dilated oesophagus (arrows). Incidental, old apical tuberculous disease. (B) HRCT demonstrates ground glass shadowing, architectural distortion with irregularity of the right oblique fissure (arrowheads), reticular opacities, and traction bronchiolectasis (small arrow). The dilated oesophagus is also noted (large arrow).

Oesophageal dilatation - This is common and useful diagnostically, as the signs of interstitial fibrosis are indistinguishable from cryptogenic fibrosing alveolitis. Aspiration pneumonia may occur. $^{126}$

Pulmonary hypertension - This is usually secondary to interstitial lung disease but may be primary. ${ }^{127}{ }^{128}$ It is relatively common, seen in $50 \%$ of patients with CREST and $33 \%$ of patients with classical PSS at angiography. ${ }^{129}$ Chest radiography is less sensitive but is very specific, with enlargement of the main pulmonary arteries and cardiomegaly. ${ }^{121} 124129$

Diffuse pleural thickening-This is seen in $20 \%$ on HRCT. ${ }^{122}$ Significant effusions are uncommon. ${ }^{1121}$

MIXED CONNECTIVE TISSUE DISEASE (MCTD)

MCTD has overlapping features of SLE, PSS, and PM/DM and increased titres of antiribonucleoprotein antibody, affecting women in their 30 s to 50 s. Lung involvement (box 7) occurs in up to $80 \%{ }^{130}$ and may be detected on chest radiography or pulmonary function tests in $69 \%$ of asymptomatic patients. ${ }^{130-132}$ Manifestations are similar to those of SLE, PSS, and PM/DM. ${ }^{131} 132$

Interstitial lung disease - This is similar to the pattern of SLE, PSS, and PM/DM and is the commonest abnormality seen on chest radiography, seen in $21 \%-85 \% .{ }^{131} 133$ Thirty per cent 


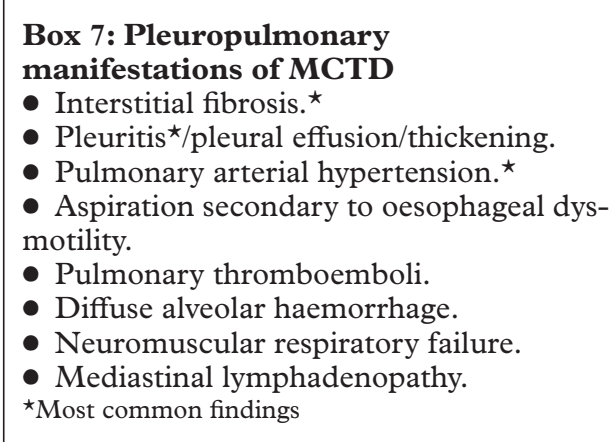

\begin{tabular}{|c|}
\hline $\begin{array}{l}\text { Box 8: Common pleuropulmonary } \\
\text { manifestations of ankylosing } \\
\text { spondylitis } \\
\text { Changes of spondyloarthritis } \\
\text { - Ankylosis of costovertebral joints. }{ }^{\star} \\
\text { - Reduced chest wall mobility. }{ }^{\star}\end{array}$ \\
\hline $\begin{array}{l}\text { Pulmonary } \\
\text { - Apical fibrobullous disease }{ }^{\star}+/- \text { myc- } \\
\text { etoma. } \\
\text { ^Most common findings }\end{array}$ \\
\hline
\end{tabular}

of patients have signs of interstitial lung disease on chest radiography at presentation. ${ }^{131}$ Histologically the appearances are of fibrosing alveolitis.

Pleural disease-This is common, with pleuritic chest pain in $40 \%$ but radiographic signs of thickening and effusions are less common. ${ }^{131} 133$

Pulmonary arterial hypertension-This has an insidious onset but may be rapidly progressive carrying significant morbidity and mortality. ${ }^{131}$ It is usually a primary vascular process due to intimal proliferation and medial hypertrophy of small arterioles but may be secondary to interstitial lung disease or chronic pulmonary emboli. The chest radiograph may be normal or have characteristic changes.

Oesophageal dysmotility-This is common $(74 \%)$ and may cause aspiration pneumonia. ${ }^{131} 133$

Diffuse alveolar haemorrhage-This has been reported and may occur with a systemic vasculitis or rarely with isolated pulmonary capillaritis. $^{49} 134$

\section{ANKYLOSING SPONDYLITIS}

This seronegative arthropathy may have extraarticular manifestations including ocular, cardiac, and pulmonary disease.

Pulmonary involvement (box 8)-This is reported in $1.3 \%-15 \% .^{62}{ }^{135}$ Patients are usually asymptomatic but may present with cough, dyspnoea, and rarely haemoptysis (from tuberculous or fungal colonisation ${ }^{62}$ ). Limitation of chest expansion, caused by ankylosis of the costovertebral joints, is common. ${ }^{136}$ Pulmonary function tests may be restrictive or less commonly obstructive. ${ }^{62}$

Chest radiography - Findings in 2080 patients with ankylosing spondylitis are reported by Rosenow et al. ${ }^{135}$ Twenty six patients (1.3\%) had apical fibrosis/fibrobullous disease (resulting in gross distortion and hilar retraction), five had mycetoma formation, three had pleural effusions, two had pneumothoraces, and two had signs of cor pulmonale. Tracheobronchomegaly (Mounier-Kuhn syndrome) has been reported. ${ }^{137}$

HRCT - This demonstrates abnormalities in $69 \%-71 \%$, including interlobular septal thickening, basal interstitial lung disease, bronchiectasis (primary and traction), emphysema, upper lobe fibrosis, pleural thickening, mycetoma formation, and mediastinal lymphadenopathy. ${ }^{62} 138$ The patients with basal interstitial lung disease had respiratory symptoms and abnormal pulmonary function tests typical of fibrosing alveolitis and no interstitial changes on chest radiography. Two patients had saber sheath trachea and two had increased tracheal dimensions with proximal bronchiectasis.

Thus, HRCT demonstrates a more extensive spectrum of pulmonary pathology compared with chest radiography.

\section{RELAPSING POLYCHONDRITIS}

Relapsing polychondritis is a rare systemic condition of unknown aetiology with recurrent, progressive inflammation and destruction of cartilage, commonly involving auricular, laryngeal, tracheobronchial, and nasal cartilage. ${ }^{139-141}$ Up to a third of patients have another autoimmune disease. ${ }^{140142143}$ Presentation is in the 40 to 60 age group $(M=F)$ with no familial predisposition. ${ }^{139140}$

\section{Airways manifestations}

Airways involvement usually presents with cough, dyspnoea, hoarseness, localised tenderness, and recurrent pneumonia. It is common $(56 \%-70 \%)$ and may carry a poor prognosis, causing approximately $50 \%$ of deaths. ${ }^{139} 144$ However, a recent study found a lower prevalence of airways disease, with few life threatening manifestations, ${ }^{140}$ possibly due to earlier diagnosis and improved treatments. Initially, airways narrowing may be due to mucosal oedema, but subsequent destruction of cartilage results in increased collapsibility with fixed airway narrowing secondary to fibrosis.

\section{Radiological appearances}

Although tracheal narrowing may be evident on the chest radiograph, computed tomography has a major role in establishing the diagnosis and in assessing response to therapy. ${ }^{145} 146$ Narrowing of the trachea and main bronchi is usually continuous, although more focal areas of stenosis are reported. ${ }^{146}{ }^{147}$ Multiple tracheal cartilages may appear expanded and calcified, due to cartilage hypertrophy and new bone formation. ${ }^{145}{ }^{147}$ Calcification may occur following steroid therapy. ${ }^{148}$ Involvement of the ears and nose help diagnostically.

HRCT may demonstrate bronchiectasis in segmental and subsegmental bronchi, with mucous plugging and bronchial wall thickening, possibly due to recurrent pneumonia secondary to proximal obstruction. ${ }^{145} 147$ 
Table 1 Nomenclature of major systemic vasculitides. Adapted table of Chapel Hill Consensus Conference ${ }^{149} 153 \star$, with permission

\begin{tabular}{|c|c|c|c|}
\hline & $\underset{\star /+}{G / N G}$ & Vessel type and additional characteristics & $\begin{array}{l}\text { Frequency of } \\
\text { pulmonary } \\
\text { involvement }\end{array}$ \\
\hline \multicolumn{4}{|l|}{ Small vessel vasculitis } \\
\hline Wegener's granulomatosis & $\mathrm{G} / \star$ & Respiratory tract involvement and vasculitis of small to medium sized vessels & $90 \%$ \\
\hline Churg-Strauss syndrome & $\mathrm{G} / \star$ & $\begin{array}{l}\text { Eosinophil-rich, granulomatous inflammation of respiratory tract and vasculitis } \\
\text { of small to medium sized vessels, associated with asthma and eosinophilia }\end{array}$ & $70 \%$ \\
\hline Microscopic polyangiitis & $\mathrm{NG} / \star$ & Few or no immune deposits, vasculitis affecting small vessels & $50 \%$ \\
\hline Henoch-Schönlein purpura & NG/+ & IgA dominant immune complexes affecting small vessels & $<5 \%$ \\
\hline Essential cryoglobulinaemic vasculitis & NG/+ & Cryoglobulin immune depositis, affecting small vessels & $<5 \%$ \\
\hline \multicolumn{4}{|l|}{ Medium vessel vasculitis } \\
\hline Polyarteritis nodosa & NG & $\begin{array}{l}\text { Medium and small arteries involved; no vasculitis in arterioles, capillaries or } \\
\text { venules }\end{array}$ & \\
\hline Kawasaki disease & NG & $\begin{array}{l}\text { Arteritis of large, medium and small arteries, associated with mucocutaneous } \\
\text { lymph nodes }\end{array}$ & \\
\hline \multicolumn{4}{|c|}{ (y) } \\
\hline Giant cell (temporal) arteritis & G & $\begin{array}{l}\text { Aorta and branches: }>50 \text { years } \\
\text { Temporal artery }\end{array}$ & \\
\hline Takayasu arteritis & G & Aorta and branches: $<50$ years & \\
\hline
\end{tabular}

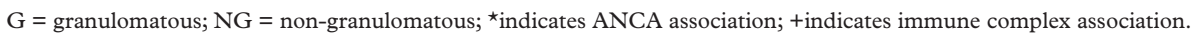

The differential diagnosis includes sarcoid, Wegener's granulomatosis, amyloidosis, and infectious perichondritis. ${ }^{146}$

\section{B. Systemic vasculitides}

The aetiology and clinical manifestations of the vasculitides are diverse, leading to difficulties in nomenclature and diagnostic criteria. The Chapel Hill Consensus Conference on the Nomenclature of Systemic Vasculitides proposed a classification based on vessel size, further refined by other distinguishing features, such as granulomatous inflammation or eosinphils. ${ }^{149}$ We have used this classification (table 1). Certain vasculitic diseases are associated with immune complex deposition and others with antineutrophil cytoplasmic antibodies (ANCA). The incidence of systemic vasculitis in the UK has been reported as 42 per million per year ${ }^{150}$ with $50 \%$ of cases being ANCA positive.

Pulmonary vasculitis may occur in the context of a primary systemic vasculitis or may be associated with an underlying disease (box 9). Pulmonary involvement is frequent in the ANCA positive small vessel vasculitides and Goodpasture's syndrome but is less common in the immune complex vasculitides.

SMALL VESSEL VASCULITIS

It is critically important to recognise and treat small vessel vasculitis early to prevent irreversible end organ damage, which may be fatal from acute pulmonary haemorrhage or tracheobronchial involvement. The previously high mortality rate has been dramatically reduced by early therapy, with improvement in $90 \%$ and complete remission in $75 \%$ in Wegener's granulomatosis. ${ }^{151}$ Lung biopsy may contribute to patient mortality. ${ }^{152}$

Wegener's granulomatosis

The classic triad includes pulmonary granulomatous inflammation, systemic small vessel vasculitis, and glomerulonephritis. During the course of the illness, 90\% have upper respiratory tract disease and $85 \%$ have pulmonary disease, with symptoms of cough, mild dyspnoea, chest pain, and haemoptysis. A third of patients may be asymptomatic, despite having abnormalities on chest radiography. ${ }^{151} 152 \mathrm{~Pa}-$ tients without renal involvement are termed "limited Wegener's granulomatosis". Wegener's granulomatosis is strongly associated with cANCA. ${ }^{153}$ Pathologically, a necrotising vasculitis affects vessels of all size, with granulomatous inflammation in pulmonary nodules.

\section{Radiological features}

Pulmonary nodules - A review of 77 patients with biopsy proved Wegener's granulomatosis demonstrated pulmonary nodules, on chest radiography and/or computed tomography, in $69 \% .^{152}$ These were well defined, irregular, and commonly bilateral varying in size from 5 to $100 \mathrm{~mm}$ (fig 5A). Half were cavitated, with thick walls. Air fluid levels were uncommon. Nodules were generally multiple, but less than 10 and increased in size and number and became cavitated during the course of untreated disease. ${ }^{152}{ }^{154}$ A computed tomography study demonstrated nodules in $88 \%$ of patients and noted scarring, spiculation, and pleural tags emanating from nodules as well as distinct feeding vessels ${ }^{155}$ (fig 5B). Peripheral wedge shaped lesions were also described, similar to pulmonary infarcts. After treatment, there may

Box 9. Pulmonary vasculitides ${ }^{153226}$ Pulmonary involvement as part of a systemic vasculitis

- Wegener's granulomatosis. *

- Churg-Strauss syndrome. *

- Microscopic polyangiitis. ${ }^{\star}$

- Goodpasture’s syndrome. ${ }^{\star}$

- Behçet's disease. *

- Henoch-Schönlein purpura.

- Essential cryoglobulinaemic vasculitis.

- Takayasu's disease.

- Giant cell (temporal) arteritis.

Pulmonary involvement in a vasculitis associated with a systemic disease

- Connective tissue disease (for example, SLE, rheumatoid arthritis, PSS).

- Paraneoplastic.

- Bronchocentric granulomatosis. Inflammatory bowel disease.

- Drug induced vasculitis.

${ }^{\star}$ Most common findings 

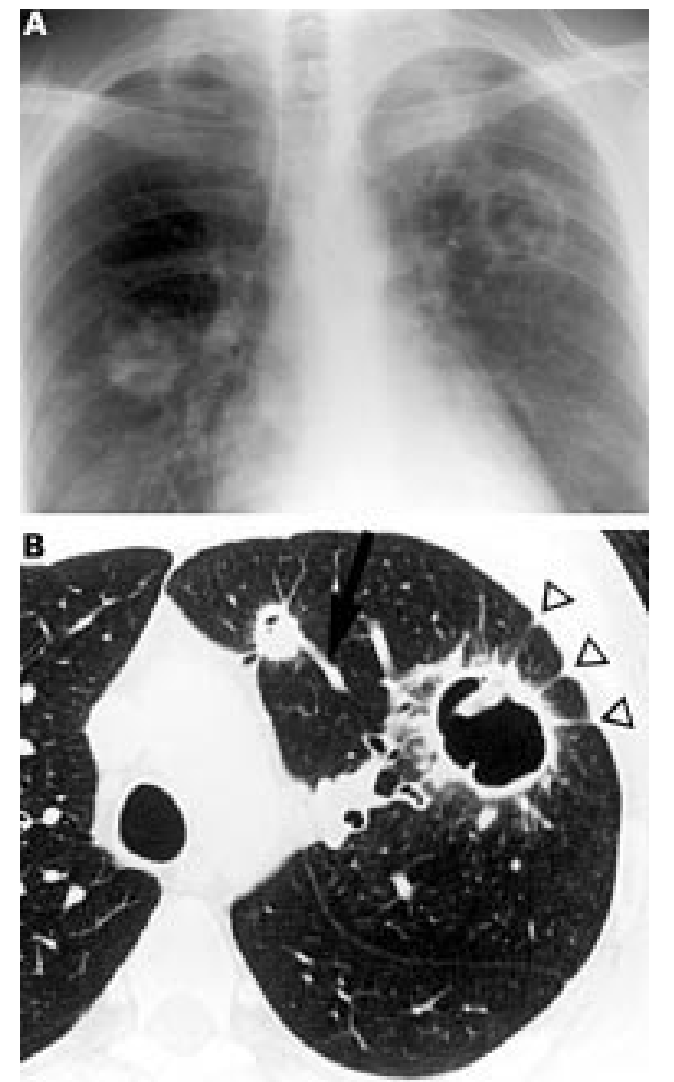

Figure 5 (A) A 35 year old man with Wegener's granulomatosis. The chest radiograph demonstrates multiple, bilateral cavitating nodules and a left apical mass. (B) HRCT demonstrates a thick walled cavitating mass in the left upper lobe with spiculation and pleural tags (arrowheads). A feeding vessel is seen running into a smaller nodule anteromedially (arrow).

be complete resolution of nodules or residual scarring.

The differential diagnosis includes pulmonary emboli (thromboembolic or septic) fungal infection and haematogenous metastases.

Air space opacities - These were seen in 50\% of cases in a review by Cordier et $a l^{152}$ and may be (1) bilateral, diffuse, or patchy areas of ground glass, which occasionally cleared spontaneously or (2) dense, localised consolidation with ill defined margins, with occasional cavitation. ${ }^{152}$ Diffuse, bilateral, low density opacities were seen in the six patients with proven alveolar haemorrhage. In children, diffuse interstitial or air space opacities are more common than nodules on chest radiography ${ }^{156}$ and computed tomography ${ }^{157}$ and are often secondary to alveolar haemorrhage.

Wegener's granulomatosis must be differentiated from Goodpasture's syndrome (both commonly involve lung and kidneys) in a patient presenting with acute alveolar haemorrhage. Wegener's granulomatosis is commonly ANCA positive, whereas antiglomerular basement membrane antibodies are present in Goodpasture's, and the latter disease is confined to the lungs and kidneys.

Tracheobronchial involvement-Tracheobronchial narrowing, presenting with stridor, is recognised but uncommon. Initially, there is florid inflammatory tissue within the lumen with subsequent fibrotic strictures. ${ }^{158}$ In tracheal involvement, spiral computed tomography demonstrates stricturing in the subglottic region in $90 \%$, with circumferential mucosal thickening. ${ }^{159}$ Vocal cords were involved in $30 \%$. Mucosal irregularity and ulceration were seen in $50 \%$ and involvement of tracheal rings, with irregular calcification and deformity, were seen in $20 \%$. Coronal reformatting is useful in determining the longitudinal extent of disease. The main bronchi may also be involved. ${ }^{159} 160$

Unusual findings - These include atelectasis, exudative pleural effusions, spontaneous pneumothorax, hilar and mediastinal lymph nodes, and calcification within an area of consolidation. ${ }^{152} 155156161$

Treatment - Treatment of the ANCA positive small vessel vasculitides, with immunosuppressives, commonly results in side effects (43\%) and dose regimens attempt to mitigate these. ${ }^{162}$ Complications include pneumonia with opportunistic organisms, which may be fatal and must be differentiated from the pulmonary vasculitis. ${ }^{152}$ There is an $80 \%$ five year survival, but disease free remission is unusual. Mortality often occurs soon after presentation, with acute pulmonary haemorrhage or in elderly patients with renal failure. ${ }^{162}$

\section{Churg-Strauss syndrome}

This pANCA associated vasculitis is distinguished from Wegener's granulomatosis by the presence of asthma and eosinophilia, with the vasculitis usually developing within three years of the onset of asthma. ${ }^{153}$ Cardiac involvement (pericarditis, myocarditis, pericardial effusions) is relatively common, causing $50 \%$ of deaths. ${ }^{163}$ Pulmonary involvement, which causes less than $10 \%$ of deaths, includes asthma, pleural effusions (which may be eosinophilic), eosinophilic infiltrations, and diffuse alveolar haemorrhage. ${ }^{164}$

\section{Radiological features}

Chest radiography-These abnormalities are common, occurring in up to $72 \%$ of cases and include transient patchy air space opacities, multiple non-segmental consolidations, which may be nodular and rarely cavitate, and diffuse interstitial opacities (fig 6). ${ }^{165-167}$ Changes are often peripheral, with no zonal predominance. Pleural effusions occur in nearly one third of cases. ${ }^{168}$ Diffuse miliary nodules and large nodules with cavitation are unusual. ${ }^{165}$ The differential diagnosis of the chest radiograph appearance includes Loeffler syndrome, allergic bronchopulmonary aspergillosis (ABPA), Wegener's granulomatosis, and microscopic polyangiitis. However distinctions can usually be made with clinical and serological features or on computed tomography (for example, confirmation of bronchiectasis in ABPA).

Computed tomography-This demonstrates ground glass or air space consolidation in 59\% (10 of 17 patients). ${ }^{169}$ A predominantly peripheral distribution was seen in six and patchy non-zonal distribution in four. Other findings include bronchiole wall and interlobular septal thickening, pulmonary nodules, and enlargement of peripheral vessels. ${ }^{167} 169$ In one case, 


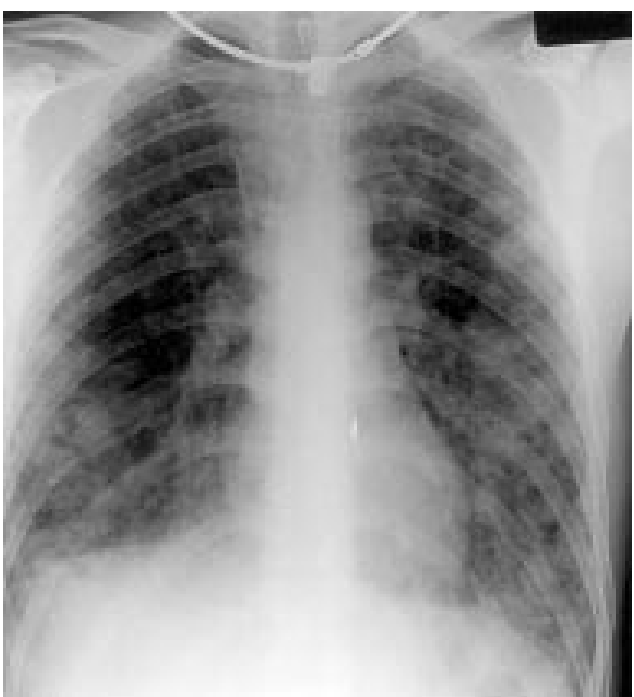

Figure 6 A 40 year old man presenting with dyspnoea, asthma, and eosinophilia. The chest radiograph demonstrates predominantly peripheral diffuse alveolar opacities, confirmed to be eosinophilic infiltrates.

histological appearances correlated well, with thickening of vessels, lymphatics, and subpleural/interlobular connective tissues due to eosinophil-rich inflammatory infiltrates, which were also seen in the intra-alveolar spaces. ${ }^{167}$

\section{Microscopic polyangiitis}

This shares many features with Wegener's granulomatosis but without granulomatous inflammation. It is strongly associated with ANCA, most often pANCA, which, together with negative hepatitis B serology help to differentiate it from (classic) polyarteritis nodosa. ${ }^{153}$ Histology confirms a small vessel vasculitis. Renal involvement occurs in $90 \%$ and pulmonary involvement in $50 \% .{ }^{153}$ It is the commonest cause of the pulmonary renal syndrome. ${ }^{170}$ Pulmonary capillaritis causing diffuse alveolar haemorrhage is the most life threatening complication. ${ }^{153}$

\section{Henoch-Schönlein purpura}

This small vessel immune complex vasculitis, predominantly affecting children, may develop after upper respiratory tract infection. There is vascular deposition of IgA dominant immune complexes. Pulmonary involvement is unusual, seen in $0 \%-6.25 \% .{ }^{171}{ }^{172}$ Diffuse alveolar haemorrhage may occur secondary to a diffuse alveolitis/capillaritis, the chest radiograph demonstrating patchy multifocal consolidations or transient ill defined infiltrations; effusions also occur. ${ }^{171} 173$ The prognosis is good, with supportive care usually being sufficient. End stage renal failure develops in $5 \% .{ }^{153}$

\section{Essential cryoglobulinaemia}

In this immune complex disease, inflammation of venules, capillaries, and arterioles is caused by accumulation of cryoglobulins. Patients present with purpura, arthralgias, and nephritis and associated hepatitis C infection. ${ }^{153}$ Pulmonary involvement is rarely reported: one series described chest radiography appearances of mild to moderate interstitial fibrosis in $78 \% .{ }^{174}$ Adult respiratory distress sydrome has also been reported. ${ }^{175}$

\section{Behçet's disease}

This clinical triad of oral and genital ulceration and uveitis is a multisystem vasculitis of unknown aetiology affecting vessels of all sizes. ${ }^{176}$ It is more common in young men from eastern Mediterranean countries and Japan. Pathognomonic laboratory or histological tests are lacking. ${ }^{177}$

Pulmonary involvement - This is estimated at $5 \%-10 \%$ of patients, usually presenting with haemoptysis. ${ }^{178} 179$ Thoracic involvement includes pulmonary thromboemboli and infarction, superior vena cava thrombosis, and pulmonary artery aneurysm. ${ }^{176}$ Histologically, there is a vasculitis, resulting in arterial aneurysms and thrombosis. ${ }^{176}$ Haemoptysis carries a poor prognosis, with a $30 \%$ mortality within two years. ${ }^{180}$ Pulmonary hypertension and right heart failure may develop.

\section{Radiological appearances}

Chest radiography findings-Airspace consolidation, seen in $56 \%$ of patients with lung involvement, is due to haemorrhage or infarction. ${ }^{181} 182$ Subpleural nodular opacities, seen in 33\%$83 \%$, may represent infarcts and occasionally cavitate, may resolve spontaneously and rarely lead to rupture into the pleural space. ${ }^{178} 181$ Hilar prominence on the chest radiograph represents dilated arteries seen on computed tomography. ${ }^{179} 181$ Mediastinal widening, seen in $56 \%$ of patients, correlated with mediastinal oedema secondary to venous thrombosis on computed tomography. ${ }^{181}$ Pleural effusions (secondary to pulmonary infarction or chylous secondary to superior vena cava obstruction ${ }^{183}$ ) were identified in $30 \%{ }^{181}$ Atelectasis and elevation of the hemidiaphragm may be due to infarction. ${ }^{179}$

Computed tomography-Pulmonary artery aneurysms, mural thrombus, and calcification may be seen. ${ }^{181} 184$ Thrombosis of the superior vena cava, with extension into the right atrium, is associated with mediastinal oedema. ${ }^{181}$ HRCT demonstrates irregular enlargement and cut offs of peripheral vessels seen longitudinally or a stellate configuration transversely. ${ }^{179}$ The differential diagnosis of the pulmonary artery aneurysms in Behçet's include giant cell arteritis, mycotic aneurysm, and malformations of the pulmonary vessels.

Pulmonary angiography - This may demonstrate aneurysms, occlusions, and thromboemboli. Angiography is hazardous with clinical deterioration in $50 \%$ and formation of aneurysms at the puncture site. ${ }^{180}$

Hughes-Stovin syndrome-This variant of Behçet's disease is the association of multiple pulmonary aneurysms with deep venous thrombosis. ${ }^{185}$ There is no oral or genital ulceration. The chest radiography appearances are indistinguishable from Behçet's.

MEDIUM AND LARGE VESSEL VASCULITIS

Pulmonary involvement is rare. Pulmonary artery thrombosis, stenosis, and post-stenotic 


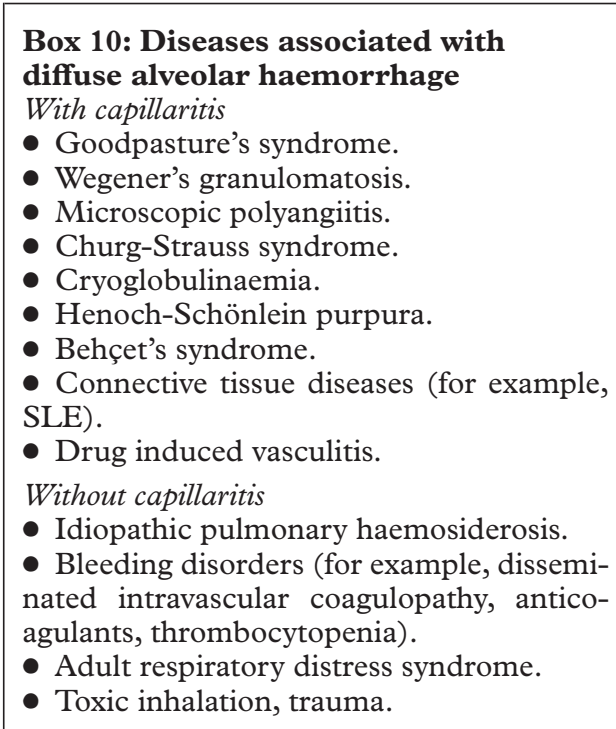

dilatation have been reported in Takayasu's arteritis. ${ }^{186} 187$ Case reports in giant cell arteritis, include recurrent bilateral cavitating pulmonary nodules, which revealed giant cell granulomas histologically, ${ }^{188}$ interstitial lung disease, ${ }^{189}$ and pulmonary artery aneurysm. ${ }^{190}$

DIFFUSE ALVEOLAR HAEMORRHAGE

Diffuse alveolar haemorrhage may occur due to a pulmonary capillaritis or in a wide variety of other diseases with no capillaritis (box 10). In pulmonary capillaritis, a necrotising vasculitis causes capillary wall necrosis, usually associated with immune complex deposition. This leads to haemorrhage into the alveoli, resulting in the clinical syndrome of diffuse alveolar haemorrhage, with haemoptysis, dyspnoea, and anaemia.

Goodpasture's syndrome originally referred to diffuse alveolar haemorrhage occurring with rapidly progressive glomerulonephritis. The term is now restricted to the presence of antiglomerular basement membrane antibodies, which are demonstrated histologically along glomerular and alveolar capillary walls.

Chest radiography-Appearances are the same regardless of the underlying cause of haemorrhage and may be normal but usually demonstrate diffuse bilateral alveolar opacities sometimes with more discrete, punctate acinar rosettes, often perihilar with sparing of the apices (fig 7). ${ }^{191} 192$ Ground glass consolidation may be seen on computed tomography. ${ }^{193}$ Rapid change in distribution of opacities may be noted, with clearing in one area and further bleeds in another. When bleeding stops, relatively rapid clearing occurs. Recurrent bleeds may lead to thickening of the alveolar basement membrane, interstitial fibrosis and haemosiderosis, which can lead to pulmonary hypertension. The appearance is difficult to distinguish from other causes of diffuse air space opacification, such as pulmonary oedema, infective consolidation or alveolar proteinosis. Bronchoalveolar lavage may be required to confirm the presence of haemorrhage or haemosiderin-laden macrophages.

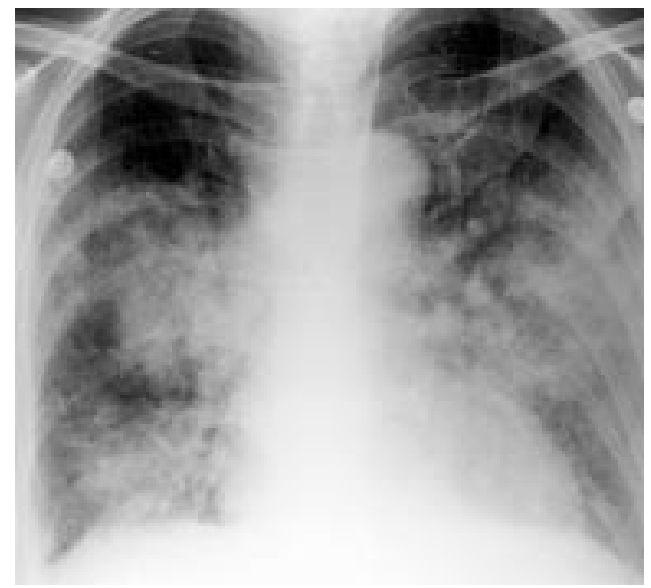

Figure 7 Female patient with a pANCA positive vasculitis and acute dyspnoea. There is bilateral patchy air space shadowing typical of haemorrhage and a small right pleural effusion.

Carbon monoxide uptake is markedly increased and is a sensitive test for diffuse alveolar haemorrhage. ${ }^{194}$

\section{Miscellaneous}

LYSOSOMAL STORAGE DISEASES

Lysosomal storage diseases are rare inherited metabolic disorders, usually autosomal recessive and most prevalent in Ashkenazi Jews. Gaucher's disease is the commonest, in which a deficiency of glucocerebrosidase activity results in accumulation and deposition of glucosyl ceramide in the reticuloendothelial system. Pulmonary involvement, seen in type 1 , leads to dyspnoea and recurrent infections, culminating in respiratory failure. ${ }^{195}$ In NiemannPick disease, the enzyme defect is sphingomyelinase, with accumulation of sphingomyelin. Presentation is in infancy or childhood. Lung involvement is variable, depending on the subtype of the disease but may cause death in infancy. ${ }^{196-198}$ BAL demonstrates lipid laden foamy macrophages. ${ }^{199}$ Diagnosis is confirmed either by bone, liver, or lung biospy.

\section{Radiological features}

Chest radiography may demonstrate alveolar opacities, a reticulonodular pattern, or bronchial wall thickening. Miliary shadowing has been reported. ${ }^{200}$ HRCT findings include interlobular septal thickening, nodules, alveolar opacities and focal air trapping ${ }^{195} 199201$ (fig 8). Infiltrative disease may lead to pulmonary hypertension.

PULMONARY AMYLOIDOSIS

Amyloid, an inert proteinaceous material, is deposited extracellularly in various organs. Pulmonary involvement may be localised or part of systemic amyloidosis. Primary systemic amyloidosis is rare but involves the lungs more commonly than in secondary disease (due to chronic infection or monoclonal gammopathy), in which pulmonary involvement is unusual. ${ }^{202}$ Patients present with cough, dyspnoea, or haemoptysis with tracheobronchial involvement (box 11). Untreated disease may be stable or progress to respiratory failure. ${ }^{203}$ 


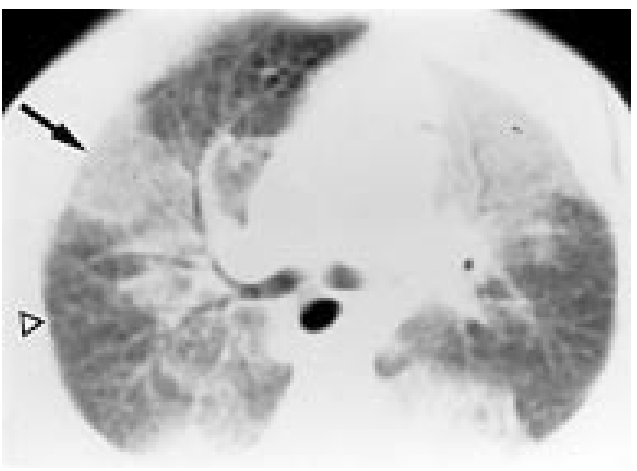

Figure 8 Computed tomography in a 4 year old girl with Gaucher's disease. Thickening of the interlobular septae (arrowhead) with ground glass opacity and air bronchograms (arrow) due to direct deposition of glucosyl ceramide.

The chest radiograph is usually normal ${ }^{204}$ with diffuse disease but may demonstrate a diffuse reticulonodular pattern, which may be associated with calcifications. There may be honeycombing. ${ }^{202}$ The radiological appearances may mimic congestive cardiac failure, secondary to cardiac amyloid, the diagnosis being made at autopsy. ${ }^{203}$ Localised disease may involve the lung parenchyma or airways. Pulmonary nodules may be solitary or multiple, may cavitate and calcify. Airways involvement is usually indolent but may cause bronchial stenosis with distal atelectasis. ${ }^{203}$ Submucosal deposits may be multifocal, plaque-like, or polypoid. Lymphadenopathy may be massive and coarsely calcified. ${ }^{202}$

Pulmonary amyloid is rare. Sarcoidosis, granulomatous infections, neoplastic disease, and cardiac failure should be excluded.

PULMONARY LANGERHANS CELL HISTIOCYTOSIS This uncommon disease of unknown aetiology usually presents in young adult smokers. There is diffuse involvement of the distal airways with granulomata, containing Langerhans cells, within the bronchial epithelium. The prognosis is variable, ranging from complete recovery to respiratory failure. ${ }^{205}$ Presentation is usually with symptoms of dry cough, chest pain, dyspnoea, or pneumothorax, although in some cases patients are asymptomatic, with changes noted on a chest radiograph. ${ }^{206}$

Box 11: Pulmonary manifestations of
amyloid
Parenchymal
• Diffuse interstitial disease. ${ }^{\star}$
- Nodules. ${ }^{\star}$
Airways
- Submucosal deposits.
- Pseudotumour appearance.
Lymphadenopathy
Pleural
• Effusions.
- Thickening.
Cardiac
• Cardiomegaly.
• Pericardial effusion.
${ }^{\star}$ Most common findings

Imaging features

The commonest chest radiography appearance is of bilateral symmetrical mid and upper zone micronodular or reticulonodular opacities, with sparing of the costophrenic angles. Larger nodules may mimic metastases. Multiple cystic air spaces and honeycombing may develop, with preservation or increase in lung volumes. $^{207} 208$ On HRCT, ${ }^{207}$ the predominant finding is of cysts (17/18) and nodules (14/18), seen more sensitively than on chest radiography. The cysts are of varying sizes and shapes, may appear confluent, septate and although usually thin walled, may have a thick wall. Nodules vary widely in size but on average are about $5 \mathrm{~mm}$. Cavitation may be present. Reticulation and ground glass is seen less frequently. The intervening lung is normal. Nodules may regress or evolve into cysts. ${ }^{209}$

The main differential diagnosis is lymphangiomyomatosis and these can be differentiated with reasonable accuracy on $\mathrm{HRCT}^{2}$ : the presence of nodules, sparing of the costophrenic angles, and the presence of non-round cysts are features compatible with Langerhans cell histiocytosis.

ERDHEIM-CHESTER DISEASE

This rare disease is caused by an infiltration of mononuclear cells. Patients have lower limb osteosclerosis and $50 \%$ have extraskeletal manifestations. Lung involvement occurs in $20 \%-30 \%$ and causes significant mortality. ${ }^{210}$ Chest radiography shows upper zone diffuse interstitial infiltrates, septal lines, and fissural thickening. Computed tomography demonstrates smooth thickening of pleura and interlobular septa, cystic areas, and ground glass opacities. Lung biopsy confirms the characteristic infiltrate of foamy histiocytes, with a striking lymphatic distribution and fibrosis. $^{210211}$

\section{PRIMARY CILIARY DYSKINESIA}

There is abnormal structure and/or function of cilia with decreased motility in respiratory, auditory and spermatocyte cilia. This leads to bronchiectasis secondary to poor clearance of bronchial mucous. It may also result in situs inversus (Kartagener's syndrome), although this is not invariable. ${ }^{212} 213$

Chest radiograph findings include bronchiectasis and hyperinflation. ${ }^{212}$ Computed tomography confirms bronchiectasis, diffuse centrilobular micronodules, and air trapping on expiratory films, ${ }^{214}$ due to small airways plugging. The diagnosis is confirmed by electon microscopy and ciliary motility studies. $^{213}$

INFLAMMATORY BOWEL DISEASE

Pulmonary involvement is rare but well established, more commonly reported in ulcerative colitis than in Crohn's disease. ${ }^{215}$ Pulmonary manifestations are diverse (box 12), however $50 \%$ are due to airways involvement, with chronic cough, which may be suppurative..$^{215} 216$ Respiratory disease usually follows the onset of bowel disease but may rarely antedate bowel symptoms. 


\section{Box 12: Pulmonary manifestations of inflammatory bowel disease \\ Airways \\ - Bronchiectasis. ${ }^{\star}$ \\ - Chronic bronchitis/suppuration. ${ }^{\star}$ \\ - BOOP. \\ - Subglottic stenosis. \\ - Chronic bronchiolitis. \\ Parenchymal \\ - Interstitial lung disease. ${ }^{\star}$ \\ - Pulmonary infiltrates with eosinophilia. \\ - Necrobiotic nodules (ulcerative colitis). \\ Pleuritis ${ }^{215}$ \\ ${ }^{\star}$ Most common findings}

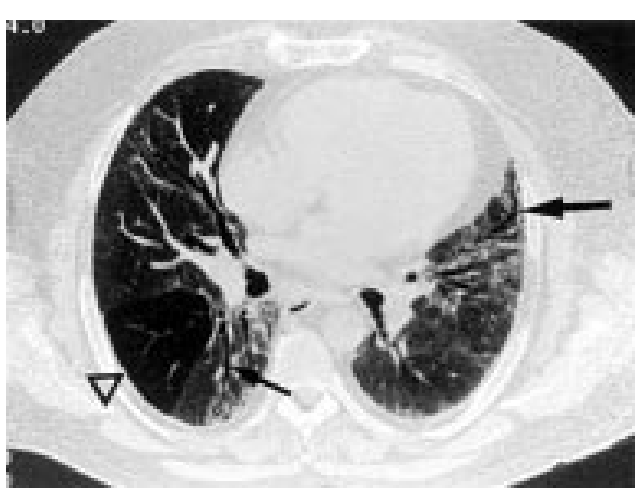

Figure 9 A 50 year old man with ulcerative colitis. HRCT demonstrates traction bronchiectasis secondary to fibrosing alveolitis (large arrow) and bronchiectasis (small arrow) with focal region of reduced attenuation and vascularity in the right lower lobe presumed secondary to small airways disease (arrowhead).

Chest radiography may demonstrate bronchial wall thickening or bronchiectasis. Computed tomography (fig 9) confirms bronchiectasis, signs of mucoid impaction, interstitial lung disease, or BOOP. ${ }^{215}{ }^{216}$ Necrobiotic nodules mimic septic emboli or Wegener's nodules. Pleural fluid may occur with a serositis. ${ }^{215}$

\section{NEUROFIBROMATOSIS}

Interstitial pulmonary fibrosis has been reported in $7 \%-20 \%$ of patients with neurofibromatosis, the pulmonary changes developing in adulthood. ${ }^{217}$

Chest radiography characteristeristics are of diffuse linear interstitial densities and large bullae distributed predominantly in the upper lobes or apical segments of the lower lobes. ${ }^{218} 219$ HRCT confirms these appearances. 220

Other non-pulmonary manifestations on the chest radiograph include neurofibromas, either intercostal, "dumbbell" (exiting the neural foramen) or in the overlying skin, intrathoracic meningoceles and changes in the ribs (ribbon ribs and rib notching due to the underlying mesenchymal defect and rib erosion by intercostal neurofibromas).

TUBEROUS SCLEROSIS/

LYMPHANGIOLEIOMYOMATOSIS

Tuberous sclerosis is a rare neuroectodermal disease with multiple hamartomas in a variety of systems. Lung involvement occurs in 1\% of cases. The clinical, histological, and radiological features of lung involvement are those of lymphangioleiomyomatosis, which is considered to be a forme fruste of tuberous sclerosis. Lymphangioleiomyomatosis is almost exclusively seen in women of reproductive age and is progressive, with a poor prognosis. Overgrowth of smooth muscle cells in the pulmonary lymphatics, blood vessels, and airways results in obstruction of the small airways with cyst formation and pneumothorax, chylothorax, and haemoptysis.

Radiological-clinical discrepancy may be seen at presentation, with severe airways limitation and a relatively normal chest radiograph. However, with disease progress, there is diffuse reticular shadowing bilaterally, with gradual hyperinflation and honeycombing. Recurrent spontaneous pneumothoraces and effusions are seen. On HRCT there is interlobular septal thickening, discrete cysts, which are uniformly distributed with no zonal predominance, and normal lung parenchyma between the cysts. ${ }^{221}{ }^{222}$ Nodules are very rarely seen. ${ }^{221}$ The differential diagnosis includes cryptogenic fibrosing alveolitis, emphysema, Langerhans cell histiocytosis, and a lymphangitic tumour. ${ }^{2}$

1 Padley SPG, Hansell DM, Flower CDR, et al. Comparative accuracy of high resolution computed tomography and chest radiography in the diagnosis of chronic diffuse infiltrative lung disease. Clin Radiol 1991;44:227-31.

2 Bonelli FS, Hartman TE, Swenson SJ, et al. Accuracy of high-resolution CT in diagnosing lung diseases. AfR 1998; 170:1507-12.

3 Swensen SJ, Aughenbaugh GL, Myers JL. Diffuse lung disease: diagnostic accuracy of CT in patients undergoing disease: diagnostic accuracy of CT in patients undergoing

4 Leung AN, Miller RR, Muller NL. Parenchymal opacifica-

Leung AN, Miller RR, Muller NL. Parenchymal opacifica-
tion in chronic infiltrative lung diseases: CT-pathologic cortion in chronic infiltrative lung diseas
relation. Radiology 1993;188:209-14.

relation. Radiology 1993;188:209-14.
5 Lee JS, Im JG, Ahn JM, et al. Fibrosing alveolitis: prognostic implication of ground glass attenuation at high-resolution CT. Radiology 1992;184:451-4.

6 Wells A, Hansell D, Rubens M, et al. The predictive value of appearances on thin-section computed tomography in fibrosing alveolitis. Am Rev Respir Dis 1993;148:1076-82.

7 Tyoshina H, Kusaba T, Yamaguchi T. Cause of death in autopsied rheumatoid arthritis patients. Ryumachi 1993;33. 209-14.

8 Sinclair R, Cruikshank B. Clinical and pathological study of sixteen cases of rheumatoid arthritis with extensive visceral involvement. O F Med 1955;25:313-32.

9 Shannon T, Gale E. Noncardiac manifestations of rheumatoid arthritis in the thorax. F Thorac Imaging 1992;7:19-29.

10 Kelly C. Rheumatoid arthritis: classical lung disease. Baillieres Clin Rheumatol 1993;7:1-16.

11 Hunninghake GW, Fauci AS. Pulmonary involvement in the collagen vascular diseases. Am Rev Respir Dis 1979;119:471503.

12 Walker W, Wright V. Rheumatoid pleuritis. Ann Rheum Dis 1967;26:467-74.

13 Shiel W, Prete P. Pleuropulmonary manifestations of rheumatoid arthritis. Semin Arthritis Rheum 1984;13:23543.

14 Tanoue L. Pulmonary manifestations of rheumatoid arthritis. Clin Chest Med 1998;19:667-85.

15 King T. Connective tissue disease. In: Schwarz M, King T, eds. Interstitial lung disease. 3rd Ed. Hamilton, Ontario: BC $51-505$.

16 Brennan SR, Daly JJ. Large pleural effusions in rheumatoid arthritis. Br F Dis Chest 1979;73:133-40.

17 Jurik A, Davidsen D, Graudal H. Prevalence of pulmonary involvement in rheumatoid arthritis and its relationship to some characteristics of the patients. Scand $\mathcal{f}$ Rheumatol 1982;12:217-24

18 Anaya JM, Diethelm L, Ortiz LA, et al. Pulmonary involvement in rheumatoid arthritis. Semin Arthritis Rheum 1995;24:242-54.

19 Dieppe P. Empyema in rheumatoid arthritis. Ann Rheum Dis 1975;34:181-5.

20 Evans M. Bilateral pneumothoraces and pleural effusions in rheumatoid lung disease. Thorax 1984;39:213-5.

21 Remy-Jardin M, Remy J, Cortet B, et al. Lung changes in rheumatoid arthritis: CT findings. Radiology 1994;193:37582. 
22 Roschmann RA, Rothenberg RJ. Pulmonary fibrosis in rheumatoid arthritis: a review of clinical features and therapy. Semin Arthritis Rheum 1987; 16:174-85.

23 Cervantes-Peres P, Toro-Perez AH, Rodriguez-Jurarado P. Pulmonary involvement in rhematoid arthritis. $\mathcal{F} A M A$ 1980;243:1715-59.

24 McDonagh J, Greaves M, Wright AR, et al. High resolution computed tomography of the lungs in patients with rheumatoid arthritis and interstitial lung disease. Br F Rheumatol 1994;33:118-22.

25 Gabbay E, Tarala R, Will R, et al. Interstitial lung disease in recent onset rheumatoid arthritis. Am f Respir Crit Care Med 1997; 156:528-35.

26 Fewins HE, McGowan I, Whitehouse GH, et al. High definition computed associated pulmonary disease. Br F Rheumatol 1991;30:214 6.

27 Sumiya $\mathrm{M}$, Ohya N, Shinoura H, et al. Diffuse interstitial pulmonary amyloidosis in rheumatoid arthritis. 7 Rheumatol 1996;23:933-6.

28 Johnson $\mathrm{T}$, White $\mathrm{P}$, Weiss $\mathrm{S}$, et al. Endobronchial necrobiotic nodule antedating rheumatoid arthritis. Chest 1982;82:199-200.

29 Burke GW, Carrington CB, Grinnan R. Pulmonary nodules and rheumatoid factor in the absence of arthritis. Chest 1977;72:538-40.

30 Yousem SA, Colby TV, Carrington CB. Lung biopsy in rheumatoid arthritis. Am Rev Respir Dis 1985;131:770-7.

31 Jolles H, Moseley PL, Peterson MW. Nodular pulmonary opacities in patients with rheumatoid arthritis. A diagnostic dilemma. Chest 1989;96:1022-5.

32 Byrd RW, Byrd RPJ, Roy TM. Rheumatoid arthritis and the pulmonary nodule. 7 Ky Med Assoc 1997;95:19-22.

33 Bakheet SM, Hammami MM, Powe J. Radioiodine uptake in rheumatoid arthritis-associated lung disease mimicking in rheumatoid arthritis-associated lung disease mimicking

34 Bakheet SM, Powe J. Fluorine-18-fluorodeoxyglucose uptake in rheumatoid arthritis-associated lung disease in patient with thyroid cancer. F Nucl Med 1998;39:234-6.

35 Mellemkjaer L, Linet M, Gridley G, et al. Rheumatoid arthritis and cancer risk. Eur F Cancer 1996;32A:1753-7.

36 Caplan A. Certain unusual radiological appearances in the chest of coal miners suffering from rheumatoid arthritis. Thorax 1953;8:29-37.

37 Geddes D, Webley H, Emerson P. Airway obstruction in rheumatoid arthritis. Ann Rheum Dis 1979;38:222-5.

38 Begin R, Masse S, Cantin A. Airway disease in a subset of nonsmoking rheumatoid patients: characterization of the disease and evidence of an autoimmune pathogenesis. $A m \mathcal{F}$ Med 1982;72:743-50.

39 Shadick NA, Fanta CH, Weinblatt ME, et al. Bronchiectasis. A late feature of severe rheumatoid arthritis. Medicine (Baltimore) $1994 ; 73: 161-70$

40 Perez T, Remy-Jardin M, Cortet B. Airways involvement in rheumatoid arthritis: clinical, functional, and HRCT findings. Am f Respir Crit Care Med 1998;157(5 pt 1):1658 65.

41 Epler GR. Bronchiolitis obliterans organizing pneumonia definition and clinical features. Chest 1992;102 (suppl):2-6.

2 Min J-K, Hong Y-S, Park S-H, et al. Bronchiolitis obliterans organizing pneumonia as an initial manifestation in patients with systemic lupus erythematosus. F Rheumatol 1997;24: 2254-7.

43 Ippolito J, Palmer L, Spector S, et al. Bronchiolitis obliterans theumatoid arthritis. Semin Arthritis Rheum 1993;23:70-8

44 Colby T, Myers J. Clinical and histologic spectrum of bronchiolitis obliterans, including bronchiolitis obliterans organising pneumonia. Semin Respir Med 1992;13:119-33.

45 Geddes DM, Corrin B, Brewerton DA, et al. Progressive airways obliteration in adults and its association with rheuairways obliteration in adults and its associati

46 Schwarz MI, Lynch DA, Tuder R. Bronchiolitis obliterans: the lone manifestation of rheumatoid arthritis? Eur Respir $\mathcal{F}$ 1994;7:817-20

47 Berendsen HH, Hofstee N, Kapsenberg PD, et al. Bronchocentric granulomatosis associated with seropositive polyarthritis. Thorax 1985;40:396-97.

48 Bonafede RP, Benatar SR. Bronchocentric granulomatosis and rheumatoid arthritis. Br $\mathcal{F}$ Dis Chest 1987;81:197-201.

4 Schwarz M, Zamora M, Hodges T, et al. Isolated pulmonary capillaritis and diffuse alveolar hemorrhage in rheumatoid arthritis and mixed connective tissue disease. Chest 1998; 113:1609-15.

50 Salaffi F, Manganelli P, Carotti M, et al. Methotrexateinduced pneumonitis in patients with rheumatoid arthritis and psoriatic arthritis: report of five cases an

51 Sostman HD, Matthay RA, Putman CE, et al. Methotrexate-induced pneumonitis. Medicine 1976;55:37188

52 Walden PAM, Mitchell-Heggs PF, Coppin C, et al. Pleurisy and methotrexate treatment. BMF 1977;ii:867.

53 Lang B, Riegel W, Peters T, et al. Low dose methotrexate therapy for rheumatoid arthritis complicated by pancytopenia and Pneumocystis carinil pneumonia. f Rheumat 1991;18:1257-9.

54 Tomioka R, King TE Jr. Gold-induced pulmonary disease: clinical features, outcome and differentiation from rheumatoid lung disease. Am $\mathcal{F}$ Respir Crit Care Med 1997;155: $1011-20$.

55 Grigor R, Edmonds J, Lewkonia R, et al. Systemic lupus erythematosus. A prospective analysis. Ann Rheum Dis erythematosus.
56 Haupt HM, Moore GW, Hutchins GM. The lung in systemic lupus erythematosus. Am f Med 1981;71:791-8.

57 Ooi GC, Ngan H, Peh WCG, et al. Systemic lupus erythematosus patients with respiratory symptoms: the value of HRCT. Clin Radiol 1997;52:775-81.

58 Pines A, Kaplinsky N, Olchovsky D, et al. Pleuro-pulmonary manifestations of systemic lupus erythematosus: clinical features of its subgroups. Prognostic and therapeutic implications. Chest 1985;88:129-35.

59 Murin S, Wiedermann H, Matthay R. Pulmonary manifestations of systemic lupus erythematosus. Clin Chest Med $1998 \cdot 19 \cdot 641-65$.

60 Turner-Stokes L, Turner-Warwick M. Intrathoracic manifestations of SLE. Clin Rheum Dis 1982;8:229-42.

61 Bankier AA, Kiener HP, Wiesmayr MN, et al. Discrete lung involvement in systemic lupus erythematosus: CT assessment. Radiology 1995;196:835-40.

62 Fenlon HM, Casserly I, Sant SM, et al. Plain radiographs and thoracic high-resolution ct in patients with ankylosing spondylitis. AfR 1997;68:1067-72.

63 Good JT, King TE, Antony VB, et al. Lupus pleuritis: clinical features and pleural fluid characteristics with special reference to pleural fluid antinuclear antibodies. Chest 1983;84:714-8.

64 Orens JB, Martinez FJ, Lynch JP. Pleuropulmonary manifestations of systemic lupus erythematosus. Rheum Dis Clin North Am 1994;20:159-93.

65 Eisenberg H, Dubois EL, Sherwin RP. Diffuse interstitial lung disease in systemic lupus erythematosus. Ann Intern Med 1973;79:37-45.

66 Miller LR, Greenberg SD, McLarty JW. Lupus lung. Chest 1985;88:265-9.

67 Fenlon HM, Doran M, Sant SM, et al. High-resolution chest CT in systemic lupus erythematosus. $A \mathscr{f} R$ 1996;166: 301-7.

68 Schurawitzki H, Stiglbauer R, Graninger W. Interstitial lung disease in progressive systemic sclerosis: high-resolution CT versus radiography. Radiology 1990;176:755-9.

69 Susanto I, Peters JI. Acute lupus pneumonitis with normal chest radiograph. Chest 1997;111:1781-3.

70 Matthay R, Schwarz M, Petty T, et al. Pulmonary manifestations of systemic lupus erythematosus: review of twelve cases of acute lupus pneumonitis. Medicine (Baltimore) 1975;54:397-409.

71 Gross M, Esterley JR, Earle RH. Pulmonary alterations in systemic lupus erythematosus. Am Rev Respir Dis 1972:105: $572-7$

72 Otsuka F, Amano T, Hashimoto N, et al. Bronchiolitis obliterans organizing pneumonia associated with systemic lupus erythematosus. Intern Med 1996;35:341-4.

73 Zamora MR, Warner ML, Tuder R, et al. Diffuse alveolar hemorrhage and systemic lupus erythematosus: clinical presentation, histology, survival and outcome. Medicine (Baltimore) 1997;76:192-201.

74 Jennings C, King TJ, Truder R, et al. Diffuse alveolar hemorrhage with underlying isolated pauciimmune pulmonary capillaritis. Am f Respir Crit Care Med 1997;155:1101-9.

75 Green RJ, Ruoss SJ, Kraft SA, et al. Pulmonary capillaritis and alveolar hemorrhage: update on diagnosis and management. Chest 1996;110:1305-16.

76 Albelda S, Gefter W, Epstein D, et al. Diffuse pulmonary hemorrhage: a review and classification. Radiology 1985; 154:289-97.

77 Hsu BY, Edwards DK, Trambert MA. Pulmonary hemorrhage complicating systemic lupus erythematosus: role of MR imaging in diagnosis. AfR 1992;158:519-20.

78 Asherson R, Higenbottam T, Xuan AD, et al. Pulmonary hypertension in a lupus clinic: experience with 24 patients. $\mathcal{F}$ Rheumatol 1990;17:1292-6.

79 Simonson J, Schiller N, Petri M, et al. Pulmonary hypertension in systemic lupus erythematosus. F Rheumatol 1989;16:918-25.

80 Asherson RA, Cervera R. Review: antiphospholipid antibodies and the lung. F Rheumatol 1995;22:62-6.

81 Wiedemann H, Matthay R. Pulmonary manifestations of systemic lupus erythematosus. $\mathcal{F}$ Thorac Imag 1992;7:1-18

82 Kassan S, Moss M, Reddick R. Progressive hilar and mediastinal lymphadenopathy in systemic lupus erythematosu on corticsteroid therapy. N Engl F Med 1976;294:1382-3. 83 Webb WR, Gamsu G. Cavitary pulmonary nodules with
systemic lupus erythematosus: differential diagnosis. AfR 1981;136:27-31.

84 Gibson GJ, Edmonds JP, Hughes GRV. Diaphragm function and lung involvement in systemic lupus erythematosus. $\mathrm{Am}$ 7 Med 1977;63:926-32.

85 Martens J, Demedts M, Vanmeenen M, et al. Respiratory muscle dysfunction in systemic lupus erythematosus. Chest 1983;84:170-5.

86 Yung R, Richardson B. Drug-induced lupus. Rheum Dis Clin North Am 1994;20:61.

87 Talal N. Sjogren's syndrome: historical overview and clinical disease spectrum. Rheum Dis Clin North Am 1992;18:50715.

88 Strimlam CV, Rosenow EC, Divertie MB, et al. Pulmonary manifestations of Sjogrens's syndrome. Chest 1976;70:35461.

89 Fairfax AJ, Haslam PL, Pavia D, et al. Pulmonary disorders associated with Sjogren's syndrome. Qf Med 1981;50:27995.

90 Deheinzelin D, Capelozzi V, Kairalla R, et al. Interstitial lung disease in primary Sjogren's. Am f Respir Crit Care Med 
91 Strimlan CV, Rosenow E, Divertie M, et al. Pulmonary manifestations of Sjogrens's syndrome. Chest 1976;70:354 61.

92 Cain H, Noble P, Matthay R. Pulmonary manifestations of Sjogren's syndrome. Clin Chest Med 1998;19:687-99.

93 Constantopoulos SH, Papadimitriou CS, Moutsopoulos HM. Respiratory manifestations in primary Sjogren's syndrome: a clinical, functional and histologic study. Chest 1985;88:226-9.

94 Franquet T, Gimenez A, Monill JM, et al. Primary Sjogren's syndrome and associated lung disease: CT findings in 50 pyndrome and associated lung

95 Gardiner P, Ward C, Allison A, et al. Pleuropulmonary abnormalities in primary Sjogren's syndrome. F Rheumatol 1993;20:831-7.

96 Fishback N, Koss M. Update on lymphoid intersitial pneumonitis. Curr Opin Pulm Med 1996;2:429-33.

97 Valesini G, Priori R, Baviollot D, et al. Differential risk of non-Hodgkin's lymphoma in Italian patients with primary Sjogren's syndrome. F Rheumatol 1997;24:2376-80.

98 Matteson E, Ike R. Bronchiolitis obliterans organizing pneumonia and Sjogren's syndrome. F Rheumatol 1990;17: 676-9.

99 Wong BC, Wong KL, Ip MS, et al. Sjogren's syndrome with amyloid A presenting as multiple pulmonary nodules. $\mathcal{F}$ Rheumatol 1994;21:165-7.

100 Hedgpeth M, Boulware D. Pulmonary hypertension in primary Sjogren's syndrome. Ann Rheum Dis 1988;47:251-3.

101 Salaffi F, Manganelli P, Carotti M, et al. A longitudinal study of pulmonary involvement in primary Sjogren's syndrome: relationship between alveolitis and subsequent lung changes in high-resolution computed tomography. $\mathrm{BrF}$ Rheumatol 1998;37:263-9.

102 Lahdensuo A, Korpela M. Pulmonary findings in patients with primary Sjogrens's syndrome. Chest 1995;108:316-9.

103 Julsrud P, Brown L, Li C, et al. Pulmonary processes of mature-appearing lymphocytes: pseudolymphoma, welldifferentiated lymphocytic lymphoma, and lymphocytic interstitial pneumonitis. Radiology 1978;127:289-96.

104 Hansen LA, Prakash UBS, Colby TV. Pulmonary lymphoma in Sjogren's syndrome. Mayo Clin Proc 1989;64: 920-31.

105 Hatron PY, Wallaert B, Gosset D, et al. Subclinical lung inflammation in primary Sjogren's syndrome. Relationship between bronchoalveolar lavage cellular analysis findings and characteristics of the disease. Arthritis Rheum 1987;30: $1226-31$.

106 Bohan A, Peter JB. Polymyositis and dermatomyositis. $N$ Engl f Med 1975;292:344-7, 403-7.

107 Schwartz MI. Pulmonary and cardiac manifestations of polymyositis-dermatomyositis. $\mathcal{F}$ Thorac Imaging 1992;7:4654

108 Dickey BF, Myers AR. Pulmonary disease in polymyositis/ dermatomyositis. Semin Arthritis Rheum 1984;14:60-76.

109 Benbassat J, Gelfel D, Larholt K, et al. Prognostic factors in polymyositis/dermatomyositis. A computer-assisted analysis of ninety-two cases. Arthritis Rheum 1985;28:249-55.

110 Frazier A, Miller R. Interstitial pneumonitis in association with polymyositis and dermatomyositis. Chest 1974;65:4037.

111 Schwartz MI, Matthay RA, Sahn SA, et al. Interstitial lung disease in polymyositis and dermatomyositis: analysis of six cases and review of the literature. Medicine $1976 \cdot 55 \cdot 89-104$.

112 Akira M, Hara H, Sakatani M. Interstitial lung disease in association with polymyositis-dermatomyositis: long-term follow-up CT evaluation in seven patients. Radiology 1999;210:333-8.

113 Tazelaar HD, Viggiano RW, Pickersgill J, et al. Intersitial lung disease in polymyositis and dermatomyositis: clinical features and prognosis as correlated with histologic findings. Am Rev Respir Dis 1990;141:727-33.

114 Ikezoe J, Johkoh T, Kohno N, et al. High-resolution CT findings of lung disease in patients with polymyositis and findings of lung disease in patients with polymyo

115 Mino M, Noma S, Taguchi Y, et al. Pulmonary involvement in polymyositis and dermatomyositis: sequential evaluation with CT $A 7 R$ 1997;169:83-7.

116 Hill C, Romas E, Kirkham B. Use of sequential DTPA clearance and high resolution computerized tomography in monitoring interstitial lung disease in dermatomyositis. $\mathrm{Br} \mathcal{F}$ Rheumatol 1996;35:164-6.

117 Sigurgeirsson B, Lindelof B, Edhag O, et al. Risk of cancer in patients with dermatomyositis/polymyositis. $N$ Engl F Med 1992;326:363-7.

118 Schwarz M. The lung in polymyositis. Clin Chest Med 1998;19:701-12

119 Schwarz M, Sutarik J, Nick J, et al. Pulmonary capillaritis and diffuse alveolar hemorrhage: a primary manifestation of and diffuse alveolar hemorrhage: a primary manifestation of
polymyositis. Am $\mathcal{F}$ Resp Crit Care Med 1995;151:2037-40.

120 Masi AT, Rodnan GP, Medsger TA, et al. Preliminary criteria for the classification of systemic sclerosis (scleroderma). Arthritis Rheum 1980;23:581-90.

121 Taormina VJ, Miller WT, Gefter WB, et al. Progressive systemic sclerosis subgroups: variable pulmonary features. $A \exists R$ 1981;137:277-85.

122 Remy-Jardin M, Remy J, Wallaert B, et al. Pulmonary involvement in progressive systemic sclerosis: sequential evaluation with CT, pulmonary function tests, and bronchoalveolar lavage. Radiology 1993;188:499-506.

123 Arroliga AC, Podell DN, Matthay RA. Pulmonary manifestations of scleroderma. $\mathcal{F}$ Thorac Imaging 1992;7:30manife.
124 Seely JM, Jones LT, Wallace C, et al. Systemic sclerosis: using high-resolution CT to detect lung disease in children. A7R 1998;170:691-7.

125 Warrick JH, Bhalla M, Schabel SI, et al. High resolution computed tomography in early scleroderma disease. $f$ Rheumatol 1991;18:1520-8.

126 Silver RM, Miller KS. Lung involvement in systemic sclerosis. Rheum Dis Clin North Am 1990;16:199-215.

127 D'Angelo WA, Fries JF, Masi AT, et al. Pathologic observations in systemic sclerosis (scleroderma). Am $7 \mathrm{Med}$ 1969;46:428-40.

128 Young R, Mark G. Pulmonary vascular changes in scleroderma. Am f Med 1978;64:998-1004.

129 Ungerer R, Tashkin D, Furst D, et al. Prevalence and clinical correlates of pulmonary arterial hypertension in progressive systemic sclerosis. Am f Med 1983;75:65-74.

involvement in mixed connective tissue disease (MCTD). Arth Rheum 1976;19:801.

131 Sullivan W, Hurst D, Harmon C, et al. A prospective evaluation emphasizing pulmonary involvement in patients with mixed connective tissue disease. Medicine 1984;63:92107

132 Derderian S, Tellis D, Abbrecht PH, et al. Pulmonary involvement in mixed connective tissue disease. Chest 1985; 88:45-8.

133 Prakash U, Luthra H, Divertie M. Intrathoracic manifestations in mixed connective tissue disease. Mayo Clin Proc 1985;60:813-21.

134 Sanchez-Guerrero J, Cesarman G, Alarion-Segovia D. Massive pulmonary hemorrhage in mixed connective tissue disease. F Rheumatol 1989;16:1132-4

135 Rosenow EC, Strimlan CV, Muhm JR, et al. Pleuropulmonary manifestations of ankylosing spondylitis. Mayo Clin Proc 1977;52:641-9.

136 Fraser RS, Pare JAP, Fraser RG, et al. Diseases of the diaphragm and chest wall. In: Fraser RS, Pare JAP, Fraser RG, et al, eds. Synopsis of disease of the chest. Philadelphia: Saunet al, eds. Synopsis of
ders, 1994: 943-65.

137 Padley S, Varma N, Flower CDR. Case report: tracheobronchomegaly in association with ankylosing spondylitis. Clin Radiol 1991;43:139-41.

138 Turetschek K, Ebner W, Fleischmann D, et al. Early pulmonary involvement in ankylosing spondylitis: assessment with thin-section CT. Clin Radiol 2000;55:632-6.

139 McAdam LP, O'Hanlan A, Bluestone R, et al. Relapsing polychondritis: prospective study of 23 patients and a review of the literature. Medicine 1976;55:193-215.

140 Zeuner M, Straub RH, Rauh G, et al. Relapsing polychondritis: clinical and immunogenetic analysis of 62 patients. F Rheumatol 1997;24:96-101.

141 Rosso AD, Petix NR, Pratesi M, et al. Cardiovascular involvement in relapsing polychondritis. Semin Arthritis Rheum 1997;26:840-4.

142 Silva J, Branco JC, Matos A, et al. Relapsing polychondritis and Reiter's syndrome. F Rheumatol 1991;18:908-10.

143 Michet CJ, McKenna CH, Luthra HS, et al. Relapsing polychondritis. Survival and predictive role of early disease manifestation. Ann Intern Med 1986;104:74-8.

144 Dolan DL, Lemmon GD, Teitelbaum SL. Relapsing polychondritis. Am f Med 1966;41:285-99.

$145 \mathrm{Im}$ JG, Chung JW, Han SK, et al. CT manifestations of tracheobronchial involvement of relapsing polychondritis. $\mathcal{F}$ Comput Assist Tomogr 1988;12:792-3.

146 Casselman JW, Lemahieu SF, Peene P, et al. Polychondritis affecting the laryngeal cartilages: CT findings. AfR 1988;150:355-6.

147 Davis SD, Berkmen YM, King T. Peripheral bronchial involvement in relapsing polychondritis: demonstration by thin-section CT. AfR 1989;153:953-4.

148 Johnson TE, Mital N, Rodnan GP, et al. Relapsing polychondritis. Radiology 1973;106:313-5.

149 Jennette J, Falk R, Andrassy K, et al. Nomenclature of systemic vasculitides: proposal of an international consensus conference. Arthritis Rheum 1994;37:187-92.

50 Scott DG, Watts RA. Classification and epidemiology of systemic vasculitis. Br f Rheumatol 1994;33:897-9.

151 Hoffman G, Kerr G, Leavitt R, et al. Wegener's granulomatosis: an analysis of 158 patients. Ann Intern Med 1992;116:488-98.

152 Cordier JF, Valeyre D, Guillevin L, et al. Pulmonary Wegener's granulomatosis: a clinical and imaging study of 77 cases. Chest 1990;97:906-12.

153 Jennette J, Falk R. Small-vessel vasculitis. N Engl f Med 1997;337:1512-23.

154 Aberle DR, Gamsu G, Lynch D. Thoracic manifestations of Wegener's granulomatosis: diagnosis and course. Radiolof Wegener's granulo
ogy 1990;174:703-9.

155 Kuhlman JE, Hruban RH, Fishman EK. Wegener granulomatosis: CT features of parenchymal lung disease. $\mathcal{F}$ Comput Assist Tomogr 1991;15:948-52.

156 Wadsworth DT, Siegel MJ, Day DL. Wegener's granulomatosis in children: chest radiographic manifestations. $A f R$ 1994;163:901-4

157 McHugh K, Manson D, Eberhard BA, et al. Wegeners's granulomatosis in childhood. Pediatr Radiol 1991;21:552-5. 58 Daum TE, Specks U, Colby TV, et al. Tracheobronchial involvement in Wegener's granulomatosis. Am 7 Resp Crit Care Med 1995;151:522-6.

159 Screaton NJ, Sivasothy P, Flower CDR, et al. Tracheal involvement in Wegener's granulomatosis: evaluation using spiral CT. Clin Radiol 1998;53:809-15.

160 Cohen MI, Gore RM, August CZ, et al. Tracheal and bronchial stenosis associated with mediastinal adenopathy 
in Wegener's granulomatosis: CT findings. 7 Comput Assist Tomogr 1984:8:327-9.

161 Epstein DM, Gefter WB, Miller WT, et al. Spontaneous pneumothorax: an uncommon manifestation of Wegener's granulomatosis. Radiology 1980;135:327-8.

162 Savage C, Harper L, Adu D. Primary systemic vascultis. Lancet 1997;349:553-7.

163 Davison AG, Thompson PJ, Davies J, et al. Prominent pericardial and myocardial lesions in the Churg-Strauss syndrome. Thorax 1983;38:793-5.

164 Lanham J, Churg J. Churg-Strauss syndrome. In: Churg A Churg J, eds. Systemic vasculitides. New York/Tokyo: Igaku-Shoin, 1991: 101-20.

165 Chumbley LC, Harrison EG, DeRemee RA. Allergic granulomatosis and angiitis (Churg-Strauss syndrome). Report and analysis of 30 cases. Mayo Clin Proc 1977;52: 477-84.

166 Degesys GE, Mintzer RA, Vrla RF. Allergic granulomatosis: Churg-Strauss syndrome. AfR 1980;135:
Allergic granulon $1281-2$.

167 Buschman DL, Waldron JA, King TE. Churg-Strauss pulmonary vasculitis. High-resolution computed tomography scanning and pathologic findings. Am Rev Respir Dis

168 Lanham J, Eldon K, Pusey C, et al. Systemic vasculitis with asthma and eosinophilia: a clinical approach to the Churg-Strauss syndrome. Medicine 1984;63:65-81

169 Worthy S, Muller N, Hansell D, et al. Churg-Strauss syndrome: the spectrum of pulmonary $\mathrm{CT}$ findings in 17 patients. AfR 1998;170:297-300.

170 Niles J, Bottinger E, Saurina G, et al. The syndrome of lung haemorrhage and nephritis is usually an ANCA-associated condition. Arch Intern Med 1996;156:440-5.

171 Cream J, Gumpel JM, Peachy RDG. Schoenlein-Henoch purpura in the adult. $Q \mathcal{F}$ Med 1970;39:461-84

172 Leavitt R, Fauci A. Pulmonary vasculitis. Am Rev Respir Dis 1986;134:149-66.

173 Markus HS, Clark JV. Pulmonary haemorrhage in 73 Markus HS, Clark JV. Pulmonary haemorrha
Henoch-Schonlein purpura. Thorax 1989;44:525-6.

Henoch-Schonlein purpura. Thorax 1989;44:525-6.
174 Bombardieri S, Paoletti P, Ferri C, et al. Lung involvement in essential mixed cryoglobulinemia. Am f Med 1979;66: $748-56$.

175 Stagg MP, Lauber J, Michalski JP. Mixed essential cryoglobulinaemia and adult respiratory distress syndrome: a case report. Am $\mathcal{F}$ Med 1989;87:445-8.

176 Efthimiou J, Johnston C, Spiro SG, et al. Pulmonary disease in Behcet's syndrome. $Q \mathcal{F}$ Med 1986;58:259-80.

177 Hasan A, Fortune F, Wilson A, et al. Role of gamma delta T cells in pathogenesis and diagnosis of Behcet's disease. Lancet 1996;347:789-94

178 Grenier P, Bletry O, Cornud F, et al. Pulmonary involvement in Behcet disease. AfR 1981;137:565-9.

179 Erkan F, Cavdar T. Pulmonary vasculitis in Behcet's disease. Am Rev Respir Dis 1992;146:232-9.

180 Raz J, Elimelech O, Chajek-Shaul T. Pulmonary manifestations in Behcet's syndrome. Chest 1989;95:585-9.

181 Ahn JM, Im JG, Ryoo JW, et al. Thoracic manifestations of Behcet syndrome: radiographic and CT findings in nine patients. Radiology 1995;194:199-203.

182 Tunaci A, Berkmen YM, Gokmen E. Pulmonary Gaucher's disease: high-resolution computed tomographic features. Pediatric Radiology 1995;25:237-8.

183 Coplu L, Emri S, Selcuk ST, et al. Life threatening chylous pleural and pericardial effusion in a patient with Behcet's syndrome. Thorax 1992;47:64-5.

184 Abadoglu O, Osma E, Ucan E, et al. Behcet's disease with pulmonary involvement, superior vena cava syndrome, chyloptysis and chylous ascites. Respir Med 1996;90:429-31.

185 Durieux P, Bletry O, Huchon G, et al. Multiple pulmonary arterial aneurysms in Behcet's disease and Hughes-Stovin syndrome. Am F Med 1981;71:736-41.

186 Lupi E, Sanchez G, Horwitz S, et al. Pulmonary artery involvement in Takayasu's arteritis. Chest 1975;67:69-74.

187 Yamada I, Shibuya H, Matsubara O, et al. Pulmonary artery disease in Takayasu's arteritis: angiographic findings. AfR 1992;159:263-9.

188 Bradley JD, Pinals RS, Blumenfeld HB, et al. Giant cell arteritis with pulmonary nodules. Am $\mathcal{F}$ Med 1984;77:13540 .

189 Karam G, Fulmer J. Giant cell arteritis presenting as interstitial lung disease. Chest 1982;82:781-4.

190 Dennison AR, Watkins RM, Gunning AJ. Simultaneous aortic and pulmonary artery aneurysms due to giant cell arteritis. Thorax 1985;40:156-7.

191 Bowley N, Steiner R, Chin W. The chest X-ray in antiglomerular basement membrane antibody disease (Goodpasture's syndrome). Clin Radiol 1979;30:419-29.

192 Muller N, Miller R. Diffuse pulmonary hemorrhage. Radiol Clin North Am 1991;29:965-71.

193 Cheah F, Sheppard M, Hansell D. Computed tomography of diffuse pulmonary haemorrhage with pathological correlation. Clin Radiol 1993;48:89-93.

194 Bowley N, Hughes J, Steiner R. The chest X-ray in pulmonary capillary haemorrhage: correlation with carbon monoxide uptake. Clin Radiol 1979;30:413-7.
195 Santamaria F, Parenti G, Guidi G, et al. Pulmonary manifestations of Gaucher disease: an increased risk for L444P homozygotes? Am 7 Respir Crit Care Med 1998;157:985-9.

196 Kovesi TA, Lee J, Shuckett B, et al. Pulmonary infiltration in Niemann-Pick disease type C. F Inherit Metab Dis 1996;19:792-3.

197 Schofer O, Mischo B, Puschel W, et al. Early-lethal pulmonary form of Niemann-Pick type $\mathrm{C}$ disease belonging to a second, rare genetic complementation group. Eur $\mathcal{F}$ Pediatr 1998;157:45-9.

198 Pin I, Pradines S, Pincemaille O, et al. [A fatal respiratory form of type C Niemann-Pick disease]. Arch Fr Pediatr :47:373-5.

199 Tabak L, Yilmazbayhan D, Kilicaslan Z, et al. Value of bronchoalveolar lavage in lipidoses with pulmonary involvement. Eur Respir $\mathcal{F}$ 1994;7:409-11.

200 Coussement A, Aiem A, Forderer A, et al. [The pure visceral form of Niemann-Pick disease in children. Review of the literature apropos of a case]. F Radiol 1988;69:783-5.

201 Ferretti GR, Lantuejoul S, Brambilla E, et al. Case report. Pulmonary involvement in Niemann-Pick disease subtype B: CT findings. F Comput Assist Tomogr 1996;20:990-2. 2 Wilson SR, Sanders DE, Delarue NC. Intrathoracic manifestations of amyloid disease. Radiology 1976;120:283-9.

203 Cordier JF, Loire R, Brune J. Amyloidosis of the lower respiratory tract. Clinical and pathological features in a series of 21 patients. Chest 1986;90:827-31.

204 Gross B, Felson B, Birnberg F. The respiratory tract in amyloidosis and the plasma cell dyscrasias. Semin Roentgenol 1986;21:113-27.

205 Howarth DM, Gilchrist GS, Mullan BP, et al. Langerhans cell histiocytosis: diagnosis, natural history, management, and outcome. Cancer 1999;85:2278-90.

206 Asamoto H, Kitaichi M, Nagai S, et al. [Pulmonary eosinophilic granuloma-clinical analysis of 17 patients]. Nihon Kyobu Shikkan Gakkai Zasshi 1995;33:1372-81.

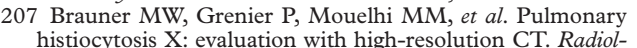
histiocytosis X: evaluat
ogy 1989;172:255-8.

208 Callebaut W, Demedts M, Verleden G. Pulmonary Langerhans' cell granulomatosis (histiocytosis $\mathrm{X}$ ): clinical analysis of 8 cases. Acta Clin Belg 1998;53:337-43.

209 Brauner MW, Grenier P, Tijani K, et al. Pulmonary Langerhans cell histiocytosis: evolution of lesions on CT scans. Radiology 1997;204:497-502.

210 Egan AJ, Boardman LA, Tazelaar HD, et al. ErdheimChester disease: clinical, radiologic, and histopathologic findings in five patients with interstitial lung disease. $A m \mathcal{F}$ Surg Pathol 1999;23:17-26.

211 Kambouchner M, Colby TV, Domenge C, et al. ErdheimChester disease with prominent pulmonary involvement associated with eosinophilic granuloma of mandibular bone. Histopathology 1997;30:353-8.

212 Nadel HR, Stringer DA, Levison H, et al. The immotile cilia syndrome: radiological manifestations. Radiology 1985; 154:651-5.

213 Bush A, Cole P, Hariri M, et al. Primary ciliary dyskinesia: diagnosis and standards of care. Eur Respir f 1998;12:982-8.

214 Homma S, Kawabata M, Kishi K, et al. Bronchiolitis in Kartagener's syndrome. Eur Respir f 1999;14:1332-9.

215 Camus P, Piard F, Ashcroft T, et al. The lung in inflammatory bowel disease. Medicine 1993;72:151-83.

216 Spira A, Grossman R, Balter M. Large airway disease associated with inflammatory bowel disease. Chest 1998;113: 1723-6.

217 Webb WR, Goodman PC. Fibrosing alveolitis in patients with neurofibromatosis. Radiology 1977;122:289-93.

218 Burkhalter JL, Morano JU, McCay MB. Diffuse interstitial lung disease in neurofibromatosis. South Med F 1986;79: 944-6.

219 Volpini E, Convertino G, Fulgoni P, et al. Pulmonary changes in a man affected by von Recklinghausen's disease. Monaldi Arch Chest Dis 1996;51:123-4.

220 White JES, Greaves M, Mohan M, et al. Breathlessness with bumps, lumps, and humps. Chest 1994;105:589-90.

221 Kirchner J, Stein A, Viel K, et al. Pulmonary lymphangioleiomyomatosis: high-resolution CT findings. Eur Radiol 1999;9:49-54.

222 Aberle DR, Hansell DM, Brown K, et al. Lymphangiomyomatosis: CT, chest radiographic and functional Radiology 1990;176:381-7.

223 Webb WR, Muller NL, Naidich DP. High-resolution CT of the lung. 2nd Ed. Philadelphia: Lippincott-Raven, 1996.

24 Wechsler RJ, Steiner RM, Spirn PW, et al. The relationship of thoracic lymphadenopathy to pulmonary interstitial disease in diffuse and limited systemic sclerosis: CT findings. AfR 1996;167:101-4.

225 Griffin MT, Robb JD, Martin JR. Diffuse alveolar hemorrhage associated with progressive systemic sclerosis. Thorax 1990;45:903-4.

226 Fulmer J, Kaltreider H. The pulmonary vasculitides. Chest 1982;82:615-24. 